\title{
Room temperature recovery of cryogenically deformed aluminium alloys
}

\author{
Belinda Gruber ${ }^{\mathrm{a}, \mathrm{b}, *}$, Florian Grabner ${ }^{\mathrm{c}}$, Georg Falkinger ${ }^{\mathrm{d}}$, Alexander Schökel ${ }^{\mathrm{e}}$, \\ Florian Spieckermann ${ }^{\mathrm{f}}$, Peter J. Uggowitzer ${ }^{\mathrm{a}, \mathrm{g}}$, Stefan Pogatscher ${ }^{\mathrm{a}, \mathrm{b}}$ \\ a Chair of Nonferrous Metallurgy, Montanuniversität Leoben, Franz-Josef-Str. 18, 8700 Leoben, Austria \\ b Christian Doppler Laboratory for Advanced Aluminum Alloys, Chair of Nonferrous Metallurgy, Montanuniversitaet Leoben, Franz-Josef Straße 18, 8700 Leoben, Austria \\ c LKR Light Metals Technologies Ranshofen, Austrian Institute of Technology, Lamprechtshausenerstr. 61, Ranshofen 5282, Austria \\ d AMAG rolling GmbH, Postfach 32, Ranshofen 5282, Austria \\ e Deutsches Elektronen Synchrotron (DESY), Notkestr. 85, 22607 Hamburg, Germany \\ ${ }^{\mathrm{f}}$ Chair of Materials Physics, Montanuniversität Leoben, Jahnstr. 12, 8700 Leoben, Austria \\ ${ }^{g}$ Laboratory of Metal Physics and Technology, Department of Materials, ETH Zürich, Vladimir-Prelog-Weg 4, 8093 Zürich, Switzerland
}

\section{H I G H L I G H T S}

- Room temperature recovery after cryogenic deformation can be divided into three different mechanistic phases

- These can be distinguished by dislocation rearrangement, dislocation annihilation and a change in strength (stress drop)

- Room temperature deformation directly after cryogenic deformation can result in immediate fracture

\section{G R A P H I C A L A B S T R A C T}

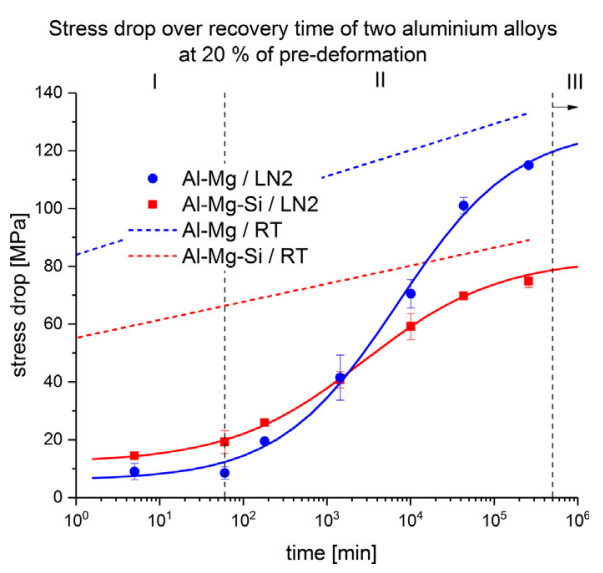

\begin{abstract}
A B S T R A C T
Increased formability of aluminium alloys has been demonstrated via cryogenic deformation. In previous studies, the microstructures of samples deformed at low temperatures were analysed after reheating to room temperature (RT) and storage. However, after heating the dislocation structure and density of the deformed material do not reflect the cryogenic situation. In this work, we investigate the evolution of flow stress during recovery in Al-Mg and Al-Mg-Si alloys. We examine the RT recovery behaviour of samples pre-strained at $77 \mathrm{~K}$ to different strain levels, and evaluate the structural stability upon subsequent deformation. We also study microstructural evolution via in-situ synchrotron X-ray diffraction, starting from initial conditions at cryogenic temperatures to long-term RT-recovery. Recovery of cryogenically deformed samples at RT results in reduction of the flow stress, in dependence on RT storage. The recovery process can be divided into three distinct sections, each based on a different mechanism characterized by either the arranging or the annihilation of dislocations. Subsequent further straining at room temperature after cryogenic forming also generates plastic instabilities and premature fracture due to unfavourable hardening and recovery assisted softening interplay.
\end{abstract}

(c) 2020 The Authors. Published by Elsevier Ltd. This is an open access article under the CC BY-NC-ND license (http:// creativecommons.org/licenses/by-nc-nd/4.0/).

\footnotetext{
* Corresponding author at: Chair of Nonferrous Metallurgy, Montanuniversität Leoben, Franz-Josef-Str. 18, 8700 Leoben, Austria. E-mail address: gruberbelinda@gmail.com (B. Gruber).
} 


\section{Introduction}

In the past few years the automotive industry has answered growing demand for lightweight materials to increase fuel efficiency and therefore diminish $\mathrm{CO}_{2}$ emissions. By using aluminium sheets in car bodies, up to $20 \%$ of total car weight can be reduced. [1]. Currently, however, various different alloys for inner and outer panels are being used which weaken the efficiency of the recycling route [2]. Here the main hindrances to a unialloy system with medium to high strength are surface quality and ductility. Production of complex structures often requires high forming limits. Al-Mg based alloys exhibit good formability, but hardening via heat treatment procedures is not possible [3]. In addition, low surface quality prevents the usage of Al-Mg based systems for exterior application or visible parts [4]. Interaction between the magnesium solute atoms and dislocations causes Lüders yielding or PLC effects (also known as dynamic strain aging) [5,6]. Both generate an uneven surface, visible in flame-shaped elevations (stretcher strain markings) or bands. Al-Mg alloys are therefore used mainly for structural or inner parts. In contrast, Al-Mg-Si alloys display better surface quality and higher strength values due to possible precipitation hardening upon paint bake treatment $[7,8]$. In the automotive industry this artificial aging treatment is applied after the last deformation step (i. e. deep drawing), simultaneously to coat drying and hardening. The main disadvantage of Al-Mg-Si alloys lies in their lower level of formability compared to Al-Mg alloys. This is also a disadvantage of aluminium alloys compared to steels in general $[1,9]$. A possible way to overcome this is to shift the forming process to higher temperatures which increases the forming limit of the alloys [10] and prevents potential PLC effects [11]. However, this can cause negative effects such as unpredicted thinning and necking, and lower age-hardening potential [12-15].

Recent studies show the advantages of deformation at sub-zero temperatures [16-24]. Schneider et al. [18] described an increase in uniform elongation of 75\% for the Al-Mg alloy EN AW 5182 when the temperature is lowered to $77 \mathrm{~K}$. In a multiaxial stress state, realized by limiting dome height experiments, a significant improvement was also achieved. Cryogenic temperatures also suppress the PLC effect thus preventing an uneven surface due to band formation and generate higher surface quality [25]. This makes it appropriate for the automotive industry to deploy Al-Mg alloys in outer panels, and renders a unialloy system possible.

Although the effect of an extended plastic deformation regime was first examined by the National Advisory Committee for Aeronautics (NASA) in 1950 [26], the mechanism behind it is still difficult to investigate due to the limits of the characterisation methods applied. Unfortunately, the directly accessible fracture surface provides few insights into the underlying deformation mechanism and microstructure [27]. Microstructural characterisation of low-temperature strained samples was typically performed after reheating to room temperature (RT). This is certainly due to the fact that sample preparation under low temperatures is hardly possible and cold insertion and measurement of the samples in the electron microscope is only feasible with special setups. Electron microscopy studies were conducted $[16,17]$ via deformation at low temperature; heating to RT for sample preparation; and storage and evaluation of the microstructure at RT. Such measurements do not provide a full picture of the deformation state at low temperatures. Hence, most research into cryogenic deformation has been conducted on samples where the microstructure was recovered to a potentially unknown extent. Moreover, another aspect is the industrial application of cryogenic deformation. Therefore it is important to understand the effects of recovery after cryogenic deformation to be able to determine final component properties. It is also crucial to understand the influence of cryogenic deformation on further RT deformation, as this is relevant in industrial post-processing.

Recovery is characterized by dislocation rearrangement and annihilation of defects to reduce the total energy of the system after deformation. Only at certain temperatures could the barrier for this processes be overcome, leading to climb and cross slip of dislocation [28-33]. Recovery due to dislocation movement is sensitive to stacking fault energy (SFE). Because the SFE of pure aluminium is high, with values of up to $250 \mathrm{~mJ} / \mathrm{m}^{2}$ [34,35] depending on the measurement method, there is a strong propensity for recovery and initial recovery processes will start even at sub-zero temperatures $[28,30,36]$. Hence, heating cryogenically deformed material to RT triggers recovery, and the dislocation structure of the deformed material changes.

The aim of this study is to determine the recovery of the lattice defects and the flow stresses after deformation at $77 \mathrm{~K}$ and RT storage in order to draw conclusions about the dislocation arrangement at the cryogenic state. Deeper insight into the mechanisms of cryogenic deformation will be possible by considering recovery for previous and future microstructural investigations. Moreover, the industrial process of cryogenic forming has not yet been fully developed and the influence of recovery on subsequent RT post-processing (e.g. multi-step forming) or final component properties will be revealed.

\section{Experimental}

\subsection{Pre-deformation and tensile tests}

Specimens were produced from aluminium sheets EN AW 51820 and EN AW 6016 T4 with a thickness of $1.2 \mathrm{~mm}$. The chemical composition of the alloys is listed in Table 1.

Pre-deformation and tensile tests were conducted using a Zwick/ Roell system with a maximum of $100 \mathrm{kN}$ loading. The sample geometry was in accordance with EN ISO 6892-3 [37] with a width of $12.5 \mathrm{~mm}$ and a reduced section of $57 \mathrm{~mm}$. All samples were mill-cut from sheets perpendicular to the rolling direction. An extensometer (Sander 20-10 O) with a gauge length of $20 \mathrm{~mm}$ was used to measure the change in length. The tensile tests were carried out at RT ( $296 \mathrm{~K})$ and under liquid nitrogen $\left(\mathrm{LN}_{2}\right)$ at $77 \mathrm{~K}$ at a strain rate of $0.008 \mathrm{~s}^{-1}$ (exceptions are specifically mentioned). The strain rate was chosen in accordance with EN ISO 6892-3 [37], but no strain rate change was made during the tensile tests, as this was not possible due to the measurement setup. During deformation at cryogenic temperatures, the reduced section of the specimens and the extensometer were kept in a Dewar filled with liquid nitrogen. The experimental setup of the cryogenic tensile tests is shown in Fig. 1. For temperature control, thermocouples were attached to the sample and inserted in the liquid nitrogen pool. At the same time, the selected strain rate prevented temperature increase in deformation zones, as enough time for heat dissipation is available. Therefore, the sample temperature was between $77 \mathrm{~K}$ and $78 \mathrm{~K}$ during the entire measurement.

Two sets of measurements were conducted. The measurements sets are simply interrupted tensile tests, which were RT-recovered at different times in the course of the interruption. Both started with predeformation at liquid nitrogen to $10 \%, 20 \%$ or $30 \%$ strain. Subsequently, the specimens were heated and stored in a Memmert IPP 400 incubator at a constant $25^{\circ} \mathrm{C}$ for 5 min to up to 6 months (recovery times were chosen on a logarithmic basis). To ensure fast heating and a measurable initial time for recovery, the samples were unloaded and detached at cryogenic temperatures, and rapidly heated by immersion in ethanol at RT. After different recovery times, tensile tests at $77 \mathrm{~K}$ or RT were performed. Each measurement was repeated three times; the error bars refer to the standard deviation. In Table 2, the two different

Table 1

Chemical composition in wt\% of EN AW 5182 and EN AW 6016.

\begin{tabular}{lllll}
\hline Alloy & $\mathrm{Mg}$ & $\mathrm{Si}$ & $\mathrm{Mn}$ & $\mathrm{Fe}$ \\
\hline EN AW 5182 O & 4.7 & 0.10 & 0.42 & 0.20 \\
EN AW 6016 T4 & 1.1 & 0.35 & 0.08 & 0.15 \\
\hline
\end{tabular}




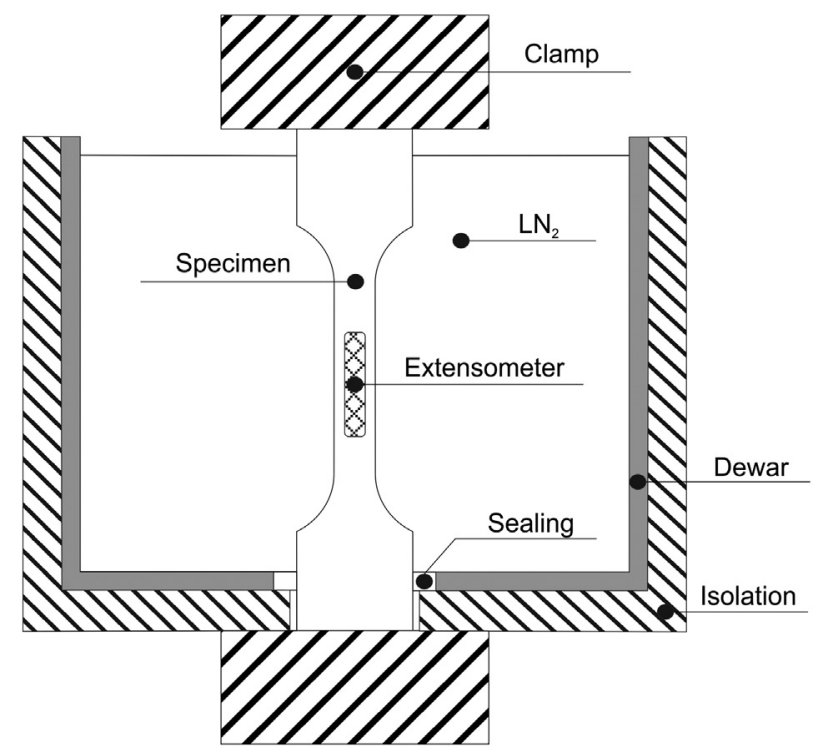

Fig. 1. Diagrammatic sketch of the experimental setup of the cryogenic tensile tests.

measurement sets are listed. All information on investigations involving final deformation until fracture at $77 \mathrm{~K}$ are given in Sections 3.2 and 4.1, "Recovery after cryogenic deformation". Samples involving final deformation at RT are summarized in Sections 3.3 and 4.2, "RT deformation after cryogenic deformation". For comparison purposes we have also carried out a third set of measurements (not listed in Table 2). These tests were done only at RT and consisted of tensile pre-deformations, recovery of unloaded specimens for 6 months, and subsequent continuation of tensile tests.

To get a better overview of the recovery processes, the stress drop between the stress level of pre-deformation and the flow onset at further straining were evaluated. Because various irregularities occur at the flow onset, the engineering stress/strain curves were transformed into true stress/strain curves. The flow stress was set in relation to the dislocation density through the Taylor eq. (1) [38]. Here, $\sigma_{0}$ is the initial yield stress, $\alpha$ a material constant, $\mu$ the shear modulus, M the Taylor factor, $\mathrm{b}$ the Burgers vector and $\rho$ the dislocation density.

$\sigma=\sigma_{0}+\alpha \mu M b \sqrt{\rho}$

In Eq. (1) the dislocation density is dependent on the strain. The evolution of the dislocation density during deformation is given by the Kocks-Mecking model in Eq. (2) [39,40] and consists of two parts. The term $k_{1} \sqrt{\rho}$ represents the dislocation generation based on plastic deformation and the term $k_{2} \rho$ the dynamic dislocation annihilation.

$\frac{d \rho}{d \varepsilon}=k_{1} \sqrt{\rho}-k_{2} \rho$

By means of the KM model, the flow curves were approximated and the difference in stress between pre-straining and the calculated flow onset after recovery evaluated. All parameters used in the modelling are listed in Table 3.

Table 2

The two different sets of measurements and their experimental parameters.

\begin{tabular}{lll}
\hline $\begin{array}{l}\text { Pre-deformation } \\
\text { [\%] }\end{array}$ & Recovery time at RT & $\begin{array}{l}\text { Further straining until } \\
\text { fracture }\end{array}$ \\
\hline 10,20 and 30 at $\mathrm{LN}_{2}$ & $5 \mathrm{~min}, 1 \mathrm{~h}, 3 \mathrm{~h}, 1 \mathrm{~d}, 1 \mathrm{w}, 1 \mathrm{~m}, 6 \mathrm{~m}$ & $\mathrm{LN}_{2}$ \\
10,20 and 30 at $\mathrm{LN}_{2}$ & $5 \mathrm{~min}, 1 \mathrm{~h}, 3 \mathrm{~h}, 1 \mathrm{~d}, 1 \mathrm{w}$ & $\mathrm{RT}$
\end{tabular}

\subsection{Synchrotron measurements}

Synchrotron measurements were performed using a fixed photon energy of $60 \mathrm{keV}$ on the Petra III beamline P02.1 at DESY (Hamburg). The beam size was $200 \times 200 \mu \mathrm{m}$ and diffraction patterns were recorded by a 2-dimensional Perkin-Elmer XRD1621 detector. The wavelength and sample to detector distance were calibrated using $\mathrm{LaB}_{6}$ (NIST660b) and $\mathrm{CeO}_{2}$ (NIST674b) standards, respectively. Similar to the tensile tests, a set of cryogenic preloaded samples was measured during heating and storage at RT. Therefore, tensile test samples of sheet material were deformed to $10 \%, 20 \%$ and $30 \%$ of strain under $\mathrm{LN}_{2}$. After unloading, sample preparation and mounting to the temperature stage were carried out in a Linkam furnace under $\mathrm{LN}_{2}$ using a solid state sample holder designed for relaxation studies [44] to create the unique possibility to study recovery processes from the moment of heating up. Diffraction patterns were recorded in-situ during heating from $77 \mathrm{~K}$ to RT and held at RT for up to $3 \mathrm{~h}$ to evaluate the recoverable fraction of dislocations upon heating and storage. Additionally, samples with a recovery time of $12 \mathrm{~h}, 24 \mathrm{~h}, 1 \mathrm{~d}, 1$ week and 1 month were measured separately. Afterwards the diffraction patterns with respect to the azimuthal range were integrated using pyFAI-software [45]. The change in dislocation density was calculated by X-ray line profile analysis using Fityk [46] for the peak position evaluation and Convolutional Multiple Whole Profile fitting (CWMP) [47,48] with a combinatorial approach to achieve a high numerical stability $[49,50]$.

\section{Results}

\subsection{Stress-strain behaviour at RT and $77 \mathrm{~K}$}

Fig. 2 shows the stress-strain curves of alloys EN AW 6016 T4 and EN AW $5182 \mathrm{O}$ at RT and $77 \mathrm{~K}$, respectively. Particularly noteworthy is the strain hardening behaviour, which is strongly temperature-dependent in both alloys.

At the onset of plastic deformation the influence of the temperature on the flow stress is rather moderate (difference between RT and $77 \mathrm{~K}$ : $\Delta \sigma \approx 30 \mathrm{MPa}$ for EN AW $6016 \mathrm{~T} 4$ and $\Delta \sigma \approx 35 \mathrm{MPa}$ for EN AW $5182 \mathrm{O}$, mainly determined by the thermally activated hardening contributions of the obstacle strength of clusters in EN AW 6016 T4 [51,52], and solid solution hardening in EN AW 51820 [53]). The temperature influence increases markedly with increasing strain. At $20 \%$ plastic strain, for example, the differences in flow stress are $\approx 80 \mathrm{MPa}$ (EN AW $6016 \mathrm{~T} 4$ ) and $\approx 100 \mathrm{MPa}$ (EN AW 51820 ), respectively. The hardening effect becomes particularly apparent in the plots in Fig. 2(b) and 1(d), where the slope of the curves provides information on the strain hardening rate. The low slopes at $77 \mathrm{~K}$ indicate that even at high strength levels considerable strain hardening occurs. It can therefore be concluded that the increase in dislocation density with plastic strain is more pronounced at $77 \mathrm{~K}$ and a higher density of lattice defects will be generated. Consequently, heating of samples that have been deformed at $77 \mathrm{~K}$ to RT may result in softening, via processes described in the next section.

Table 3

Defined parameters for the calculation of the flow curves [41-43].

\begin{tabular}{lll}
\hline Parameter & Value & Unit \\
\hline$\sigma_{0,6016 \text { LN2 }}$ & 138 & $\mathrm{MPa}$ \\
$\sigma_{0,5182 \text { LN2 }}$ & 152 & $\mathrm{MPa}$ \\
$\alpha$ & 0.6 & - \\
$\mu$ & $2.83 \cdot 10^{4}$ & $\mathrm{MPa}$ \\
$\mathrm{M}$ & 3.06 & - \\
$\mathrm{b}$ & $2.810^{-10}$ & $\mathrm{~m}$ \\
$\rho_{0}$ & $1 \cdot 10^{-10}$ & $\mathrm{~m}^{-2}$ \\
\hline
\end{tabular}



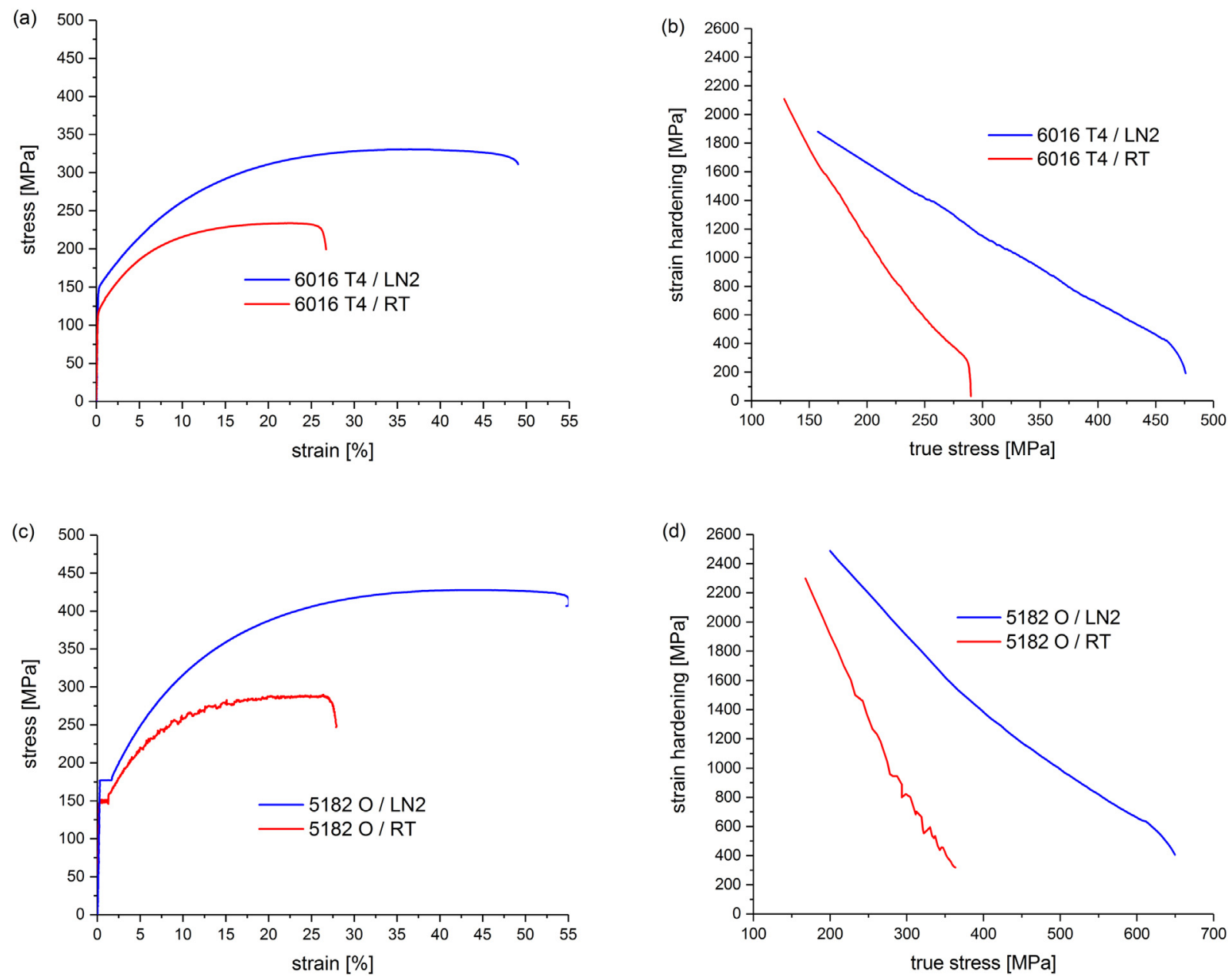

Fig. 2. Tensile test curves of alloys EN AW 6016 T4 and EN AW 51820 at $296 \mathrm{~K}$ and $77 \mathrm{~K}(\mathrm{a}, \mathrm{c}$ ) and corresponding strain hardening plots (b,d).

\subsection{Recovery after cryogenic deformation}

In Fig. 3 and Fig. 4 tensile test curves of alloy EN AW 6016 T4 and EN AW $5182 \mathrm{O}$ at $77 \mathrm{~K}$ are shown where the tests were interrupted and the samples recovered at RT for a certain time. Each measurement consists of a pre-deformation at $77 \mathrm{~K}$ with subsequent unloading and $\mathrm{RT}$ recovery, and afterwards final straining until fracture at $77 \mathrm{~K}$. Except for the curve for 5 min of intermediate RT recovery, all other curves are shifted vertically by $-25 \mathrm{MPa}$ each to improve the visibility of the effects present. Note that the curves are displayed only to uniform elongation. For longer recovery times between pre-deformation and final deformation the yield stress of the second curve decreases. For short recovery times this drop is not as pronounced. However, the onset of flow at the second straining of the samples needs attention. Two cases were observed: a pronounced plateau-like area with constant or slightly negative slope and a yield point followed by a stress decrease. The evolution of the onset flow is best illustrated by alloy EN AW 6016 T4. The tensile test curves with $10 \%$ pre-strain in Fig. 3(a) show no plateau but only a stress drop after the yield point. At 20\% pre-deformation (Fig. 3(b)) the plateau occurs between $5 \mathrm{~min}$ and $3 \mathrm{~h}$, followed by stress decrease. Similar to this, Fig. 3(c) with $30 \%$ pre-straining displays a wide plateau at 5 min, even with a drop in stress compared to the prestraining curve. After 1 day, the plateau has disappeared. A similar sequence is visible for alloy EN AW $5182 \mathrm{O}$ in Fig. 4. In every predeformation state a plateau with a negative slope appears within $3 \mathrm{~h}$ of storage at RT, followed by a yield point with a subsequent stress drop. At $10 \%$ and $20 \%$ pre-deformation a slight stress overshoot also appears. Where there is very short RT recovery this can happen to EN AW 5182 O with a slightly higher flow onset than when predeformation is stopped.

As seen in Fig. 3 and Fig. 4 it is difficult to access the actual stress drop due to stress plateaus and yield points followed by a stress decrease evolution. For a more detailed evaluation and to bypass uncertainties in the flow onset, the stress drop after recovery was determined by back extrapolation of the yield point from the flow curve with the KM model. A more detailed description can be found in the supplementary.

In Fig. 5 the stress drop derived upon RT recovery is displayed for alloys EN AW 6016 T4 and EN AW 5182 O. For guidance purposes, the inclined dashed lines of corresponding colour show the theoretically maximum achievable recovery, calculated by the difference in strength between flow curves deformed to identical strain at RT and $77 \mathrm{~K}$. They consider also the RT recovery of RT-deformed samples, which is expressed in the slope of the lines. This slope was assumed to be linear logarithmic $[54,55]$ and defined by the initial difference in strength between flow curves at RT and $77 \mathrm{~K}$ and after 6 months of recovery. Because $30 \%$ strain was not achievable at RT tensile testing due to failure at lower strain (see Fig. 2), the flow curves were extrapolated using the KM approach.

Both alloys in Fig. 5 display a minor stress drop after heating to RT at short times, before recovery accelerates. Past this onset, the kinetics changes at approximately $1 \mathrm{~h}$ for EN AW 6016 T4 and $5 \mathrm{~h}$ for EN AW 5182. Afterwards an increase in recovery generates a faster stress reduction until it slows down again. Following this decrease in recovery, the slope is similar to the stress drop of RT-deformed samples. The slowing 

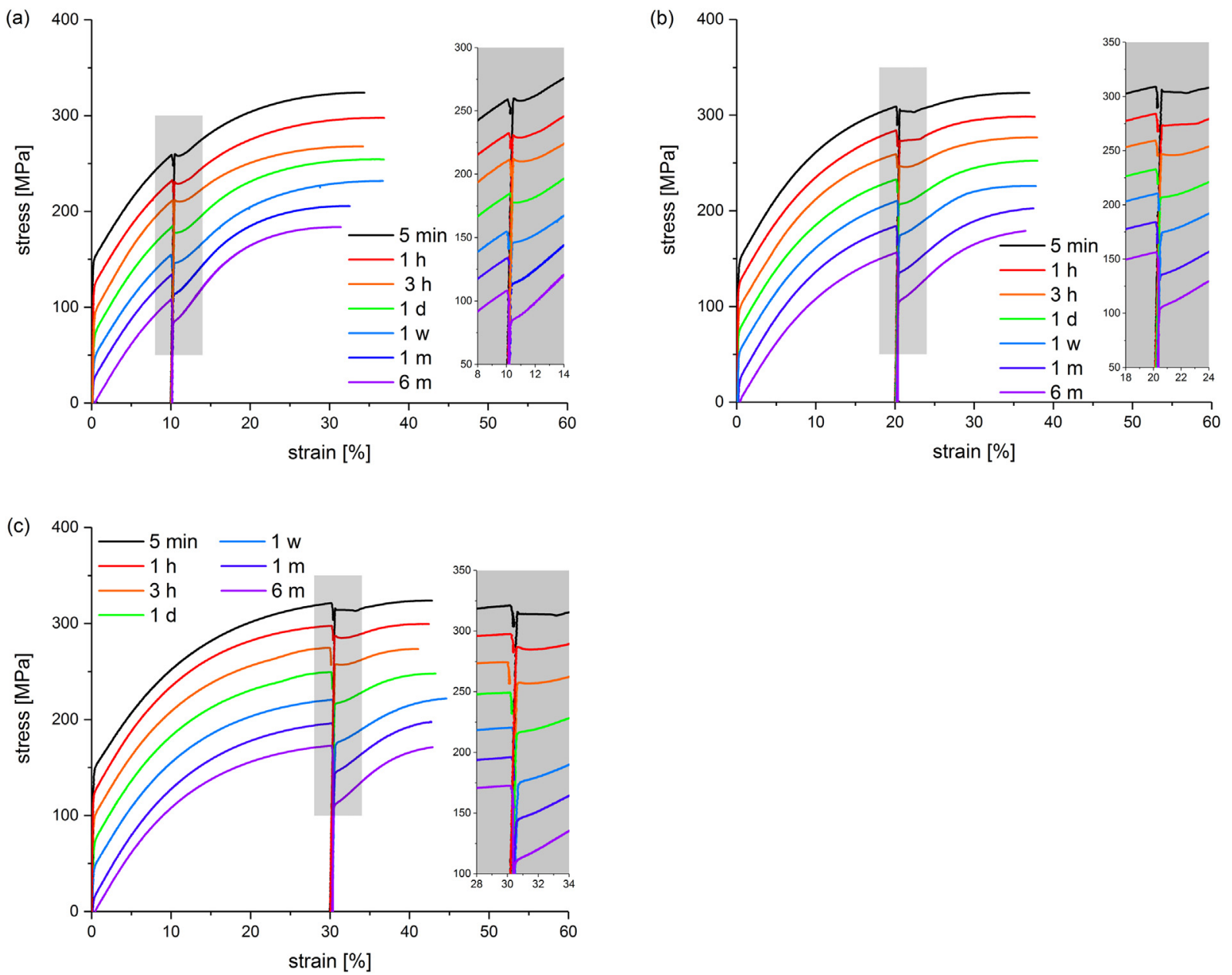

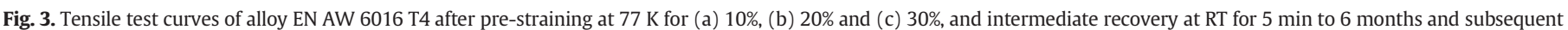
deformation at $77 \mathrm{~K}$. All curves are displayed to uniform elongation and except 5 min are shifted by $-25 \mathrm{MPa}$ for better visibility of the effects.

down of the recovery rate is only visible after 6 months or longer and is therefore at the limit of the observation period. These three different stages of recovery are separated by grey, vertical, dashed lines.

\subsection{RT deformation after cryogenic deformation}

In addition to the interrupted RT-recovered tensile tests at $77 \mathrm{~K}$, a second experimental set was performed to gain knowledge of the remaining RT deformation behaviour after cryogenic pre-deformation. As illustrated in Fig. 6 and Fig. 7, samples of alloys EN AW 6016 T4 and EN AW $5182 \mathrm{O}$ were pre-strained at $77 \mathrm{~K}$, stored at RT for periods of 5 min to 1 week, and afterwards tensile tested at RT. The only difference to the previous measurements was that the final straining was carried out at RT and not at $77 \mathrm{~K}$.

Fig. 6(a) displays this treatment after $10 \%$ of cryogenic predeformation for alloy EN AW 6016 T4. If the final tensile test at RT is performed shortly after heating (i.e. $5 \mathrm{~min}$ ), limited elongation is observed. However, the elongation recovers after $1 \mathrm{~h}$ of RT storage. With longer RT recovery, minor changes in the flow onset are visible but the reachable elongation remains the same. In Fig. 6(b) and (c) with $20 \%$ and $30 \%$ of pre-deformation at $77 \mathrm{~K}$, short recovery (up to $3 \mathrm{~h}$ ) causes immediate fracture at further RT deformation. Interestingly, significant further deformation potential could be achieved after 1 day (20\%) or 1 week $(30 \%)$ of RT recovery.

The behaviour of alloy EN AW 51820 in Fig. 7 shows the same trend, but at RT jagged tensile test curves are obtained due to the known interaction of magnesium in solid solution with the dislocations. Similarly to alloy EN AW 6016 T4 at higher pre-deformation, additional elongation is only possible after 1 day and 1 week of RT storage. However, even $5 \mathrm{~min}$ of recovery are sufficient to ensure further deformability in the $10 \%$ pre-deformed samples.

In Fig. 6(a) the 5 min RT recovery curve is of particular interest, as it is close to immediate fracture. To gain additional information the strain rate was varied from $0.008 \mathrm{~s}^{-1}$ to $0.08 \mathrm{~s}^{-1}$ and $0.0008 \mathrm{~s}^{-1}$. The results, illustrated in Fig. 8, reveal that at lower strain rates failure appears earlier, i.e. instantly after yielding. At the higher strain rate of $0.08 \mathrm{~s}^{-1}$ a further $12 \%$ elongation can be applied, comparable to that applied to the specimens stored for $1 \mathrm{~h}$ at RT.

\subsection{Dislocation densities}

Fig. 9 and Fig. 10 compare the dislocation densities over RT recovery time of EN AW 6016 T4 and EN AW $5182 \mathrm{O}$ after deformation at $77 \mathrm{~K}$. The data was acquired by two different means. On the one hand the dislocation density was simply calculated from the tensile test curves in Fig. 3 and Fig. 4 by back extrapolation with the KM model (Fig. 9 (a) and Fig. 10(a)). The solid lines represent the dislocation density with recovery time after varied pre-deformation at $77 \mathrm{~K}$. For comparison, the dashed lines show values for recovery after simple deformation at RT which were also deduced from tensile tests (compare with Fig. 5). On the other hand data from X-ray line profile analysis from synchrotron measurements are displayed (Fig. 9(b) and Fig. 10(b)). 

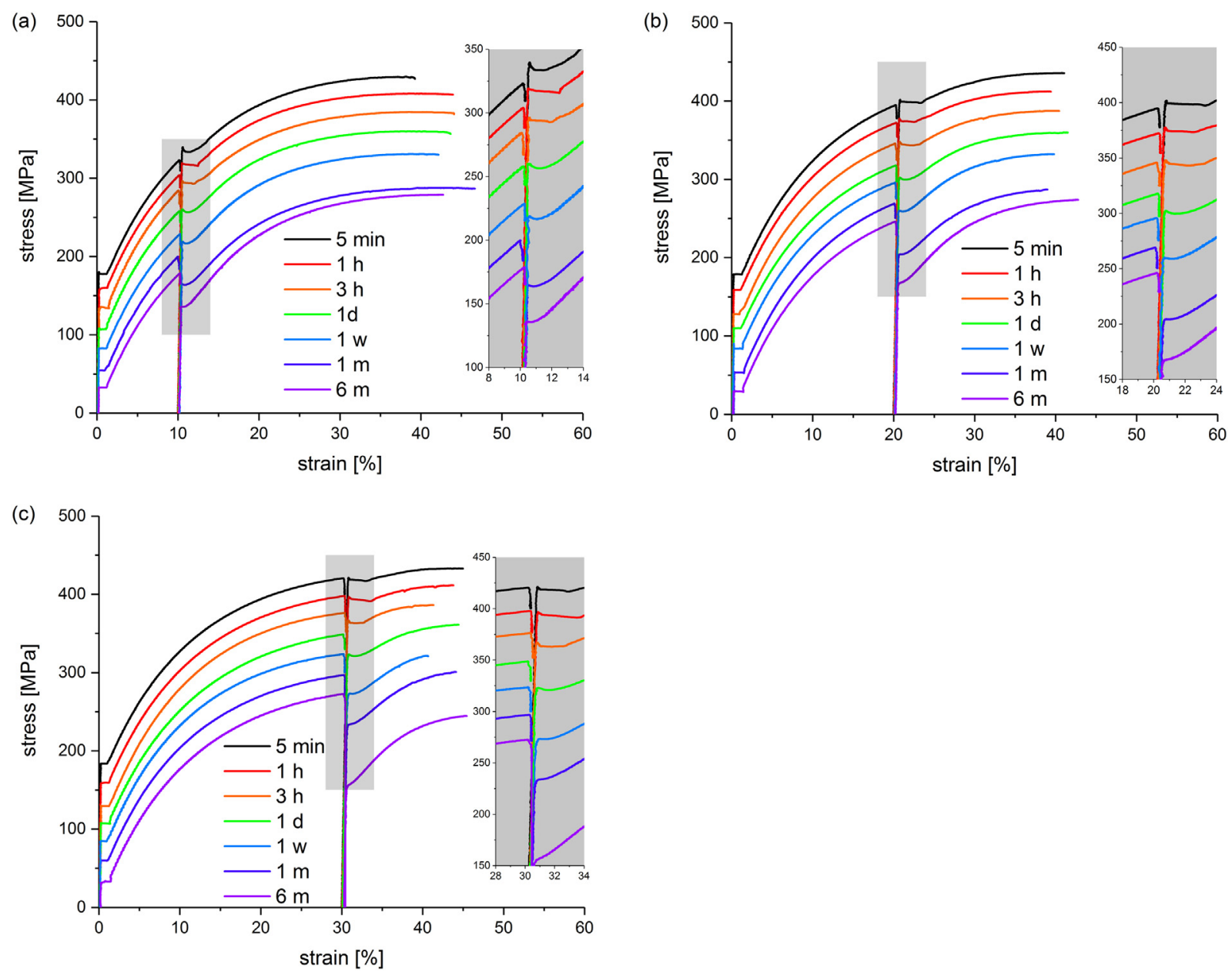

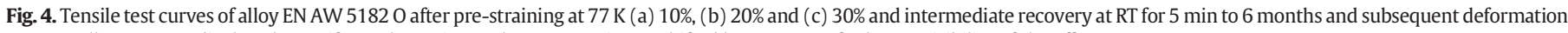
at $77 \mathrm{~K}$. All curves are displayed to uniform elongation and except $5 \mathrm{~min}$ are shifted by $-25 \mathrm{MPa}$ for better visibility of the effects.

The results from the tensile tests predict an immediate minor decline in dislocation density for the samples pre-deformed at $77 \mathrm{~K}$, followed by a rapid drop. After long recovery times of up to 6 months this drop in dislocation density is reduced. Compared to the synchrotron measurement in Fig. 9(b) and Fig. 10(b), the trend of decreasing dislocation density is the same, but tends to higher values. Another difference is that the data from synchrotron measurements show no initial changes in dislocation density. This is even more pronounced for EN AW 51820 (Fig. 10 (b)). Note that in contrast to the dislocation densities deduced from the tensile tests the synchrotron measurements also include the in-situ heating of the pre-strained samples from $77 \mathrm{~K}$ to $296 \mathrm{~K}$.
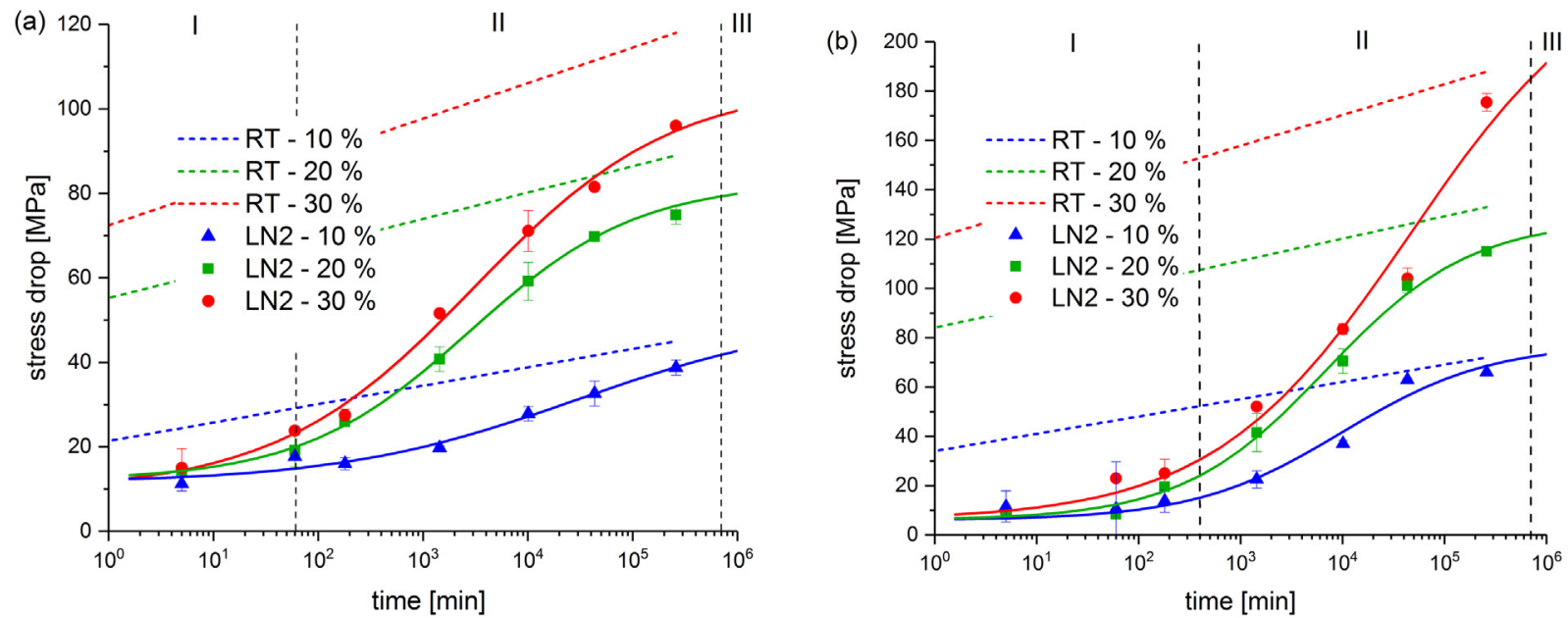

Fig. 5. Stress drop after deformation at $77 \mathrm{~K}$ over RT recovery time for alloys (a) EN AW $6016 \mathrm{~T} 4$ and (b) EN AW $5182 \mathrm{O}$ for different pre-straining. 

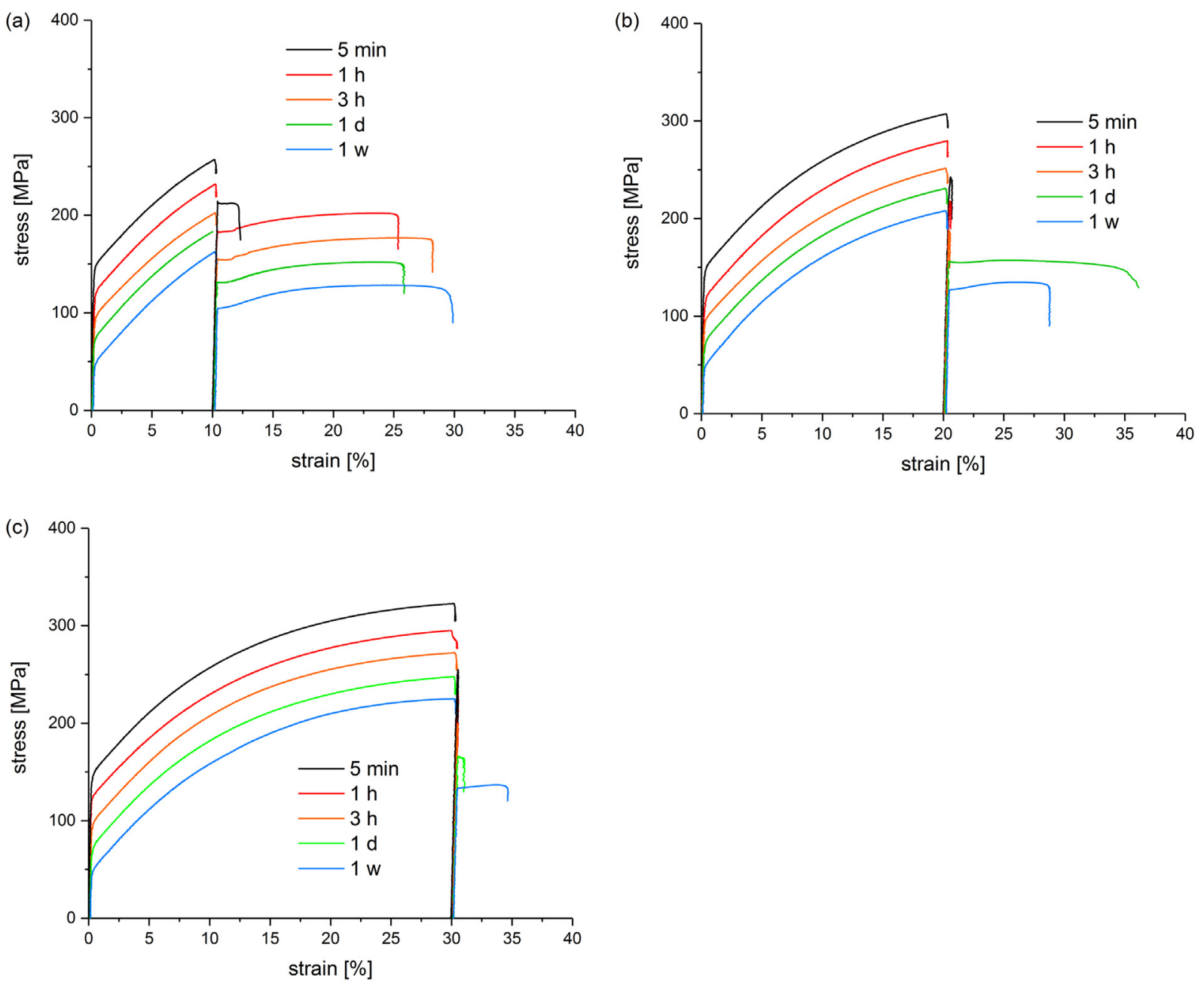

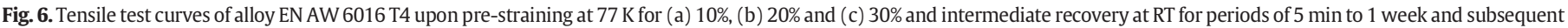
deformation at RT. All curves except $5 \mathrm{~min}$ are shifted by -25 MPa for better visibility of the effects.

\section{Discussion}

We have probed the deformation and recovery behaviour of the two alloys EN AW $5182 \mathrm{O}$ and EN AW $6016 \mathrm{~T} 4$ at RT and $77 \mathrm{~K}$ via tensile tests, measurements of the dislocation densities by X-ray line profile analysis from synchrotron, and a simple KM modelling approach. At low temperatures a lower annihilation of the dislocations occurs and strain hardening stays at higher levels. Heating samples to RT results in complex recovery phenomena which creates various types of distinct flow onset behaviour upon reloading, which will be discussed in Section 4.1.

Further RT deformation of cryogenically pre-deformed samples can even lead to direct failure. However this depends on the degree of cryogenic pre-deformation, type of alloy and strongly on the applied strain rate at RT. Mechanisms and technological implications behind this unexpected behaviour are discussed in Section 4.2 .

\subsection{Recovery after cryogenic deformation}

Fig. 5 provides the best overview of the processes during RT recovery of samples deformed at $77 \mathrm{~K}$. Note that the shape of the stress drop due to RT recovery over recovery time in Fig. 5 cannot be modelled by introducing a simple static recovery term to the KM model for either of the two alloys. Such term for static recovery is usually impacted by vacancy-assisted dislocation climb and is reported to be negligible at temperatures below $300 \mathrm{~K}$ in aluminium alloys [41,56]. The curves from Fig. 5 cannot even be reduced to a trivial linear logarithmic scale as typically seen for recovery after conventional RT deformation $[54,55]$. In summary, the observed recovery process can be divided into three stages. As described, both alloy systems initially show only a slight stress drop in the first few hours after heating up to RT (i), with a minor dependence to the applied pre-strain. After this phase the recovery increases rapidly (ii) until saturation starts (iii). The increase (ii) and the time to saturation (iii) depends strongly on the pre-deformation. A similar behaviour has also been observed after deformation during static recovery at elevated temperatures [57]. This was caused by recrystallization processes, which could not take place here. In the following the observed three stage behaviour is discussed.

\subsubsection{Stage I}

The first stage of recovery (i) starts directly after heating, when the tensile test curves in Fig. 3 and Fig. 4 show a change in the type of flow onset. The development of a yield point with stress decrease and stress plateaus indicate initial recovery processes. The plateaus cannot be ascribed to Lüders yielding caused by magnesium in solid solution for at least two reasons. Firstly, alloy EN AW 6016 T4 in natural aged condition contains a very low content of magnesium atoms in solid solution and also displays the respective behaviour. Although dissolution of $\mathrm{Mg}$-Si clusters after extensive dislocation cutting may increase $\mathrm{Mg}$ in solid solution, the maximum possible amount for achieving Lüders yielding does not match the observations of several authors 

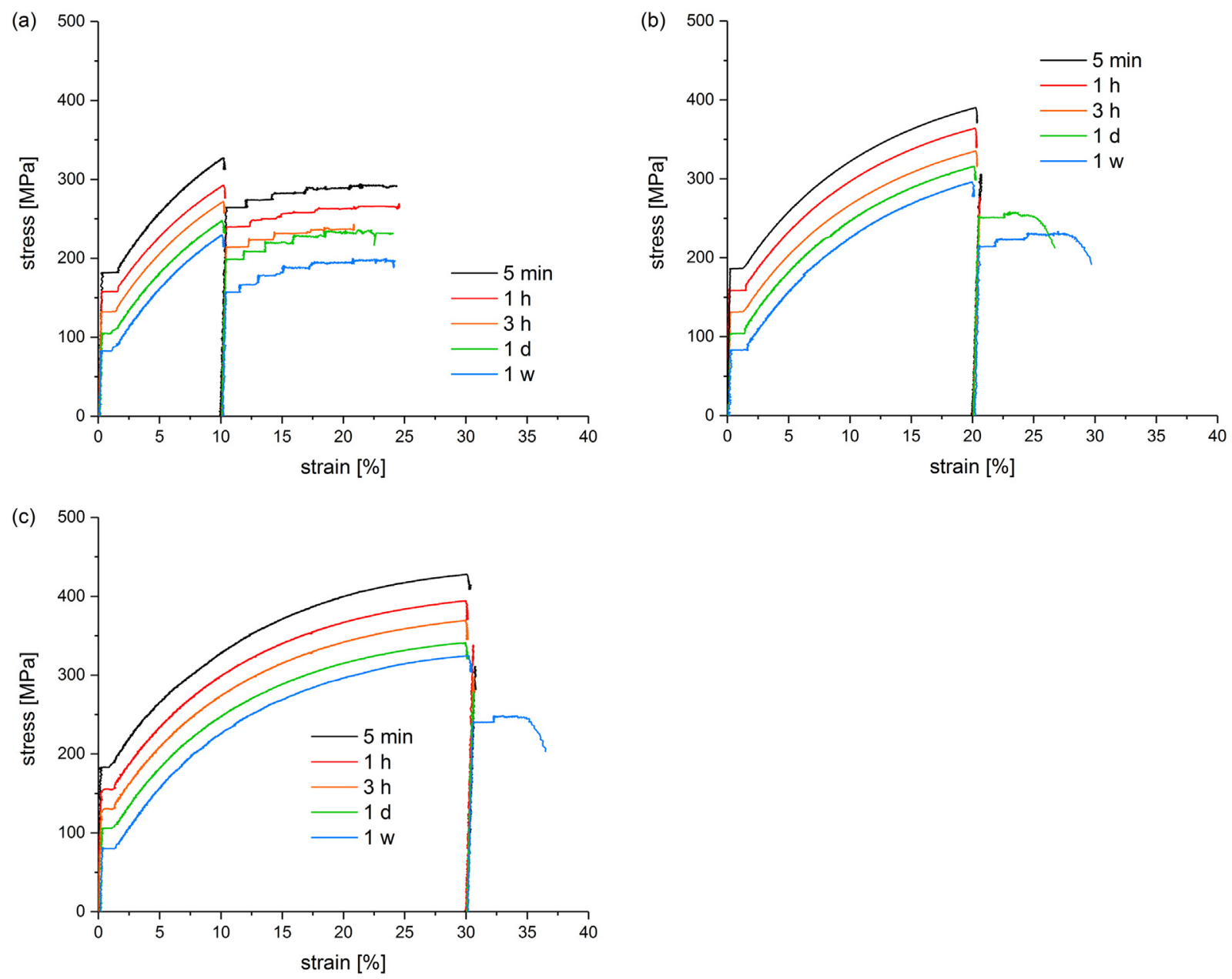

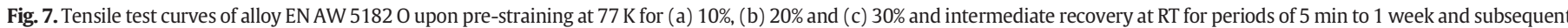
deformation at RT. All curves except 5 min are shifted by $-25 \mathrm{MPa}$ for better visibility of the effects.

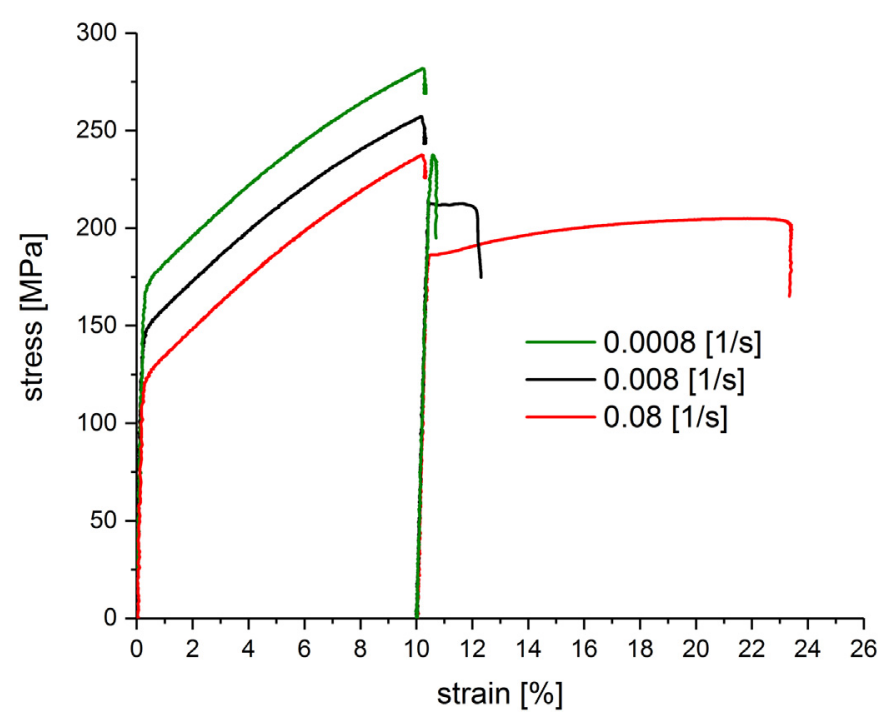

Fig. 8. Influence of strain rate on tensile test curves of alloy EN AW 6016 T4 upon prestraining at $77 \mathrm{~K}$ for $10 \%$, intermediate recovery at RT for $5 \mathrm{~min}$ and subsequent deformation at RT. All curves except $0.008 \mathrm{~s}^{-1}$ strain rate are shifted by $-25 \mathrm{MPa}$ for better visibility of the effects.
$[5,6,58,59]$. Secondly, these "stress plateaus" occur and also vanish in alloy EN AW 51820 after longer recovery times and exhibit mostly negative slopes. We suggest that these observed stress-plateaus can be seen as dislocation rearrangement triggered by applying stress. This is supported by the fact that during long term recovery first rearrangement processes and also dislocation annihilation took already place, the plateaus do not occur anymore. A detailed explanation for this assumption is further given below on the discussion of strain hardening.

In alloy EN AW $5182 \mathrm{O}$ a slight stress overshoot also appears, which even produces an increased flow onset after short RT recovery. This could be explained by the migration of vacancy-Mg to dislocations or the direct interaction of $\mathrm{Mg}$ [60] with dislocations generating a strong dislocation-solute interaction [61]. At RT deformation of this alloy, dynamic strain aging would occur, stemming from the interaction between dislocations and these complexes [62] or single Mg atoms [60]. In the case of interrupted deformation at $77 \mathrm{~K}$, the $\mathrm{Mg}$ interactions with mobile dislocations appears during RT storage. Hence the stress overshoot is assumed to result from "frozen-in dynamic strain aging". Simultaneously to the strong interaction between $\mathrm{Mg}$ and dislocations always recovery processes occur. However, at low pre-deformations and times, the recovery processes are less pronounced and a stress overshoot is clearly visible. With prolonged storage at RT, the recovery becomes more predominant and no increase in strength is visible. At $30 \%$ of pre-deformation the dislocation density is higher and hence the driving force for recovery. As a result, the recovery predominates and the stress overshoot is no longer noticeable. 

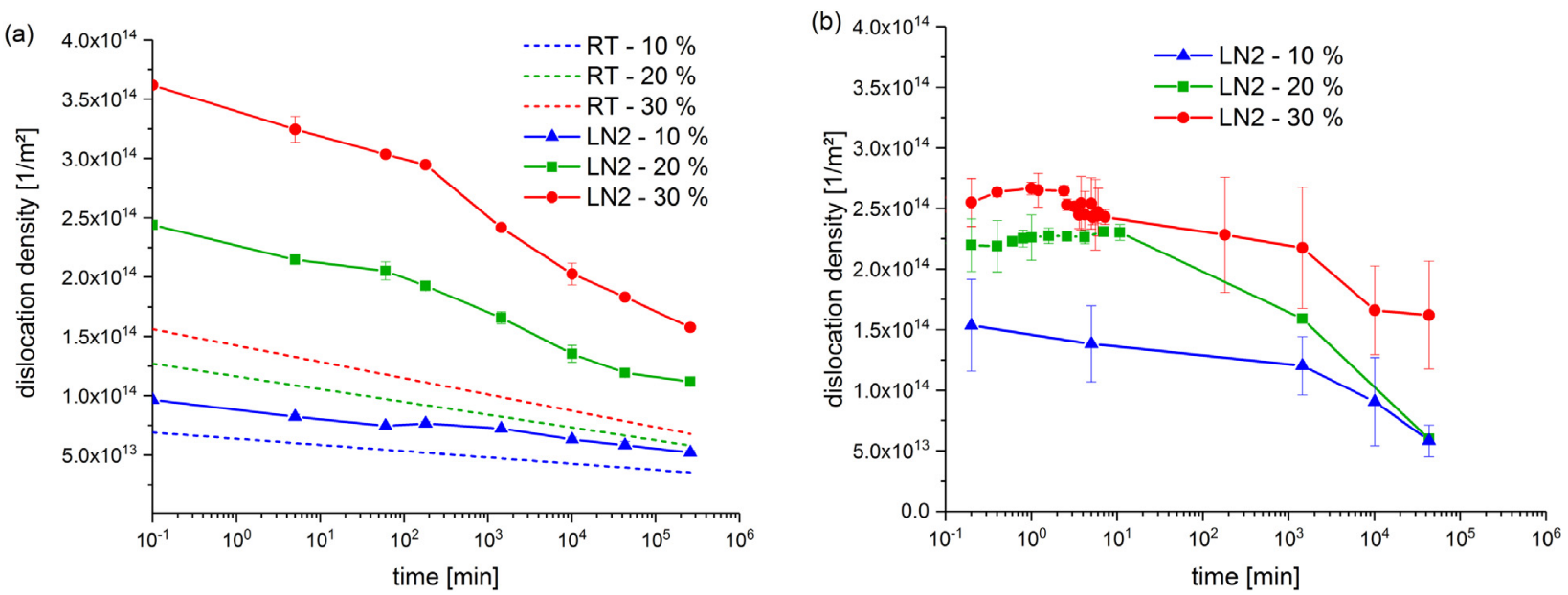

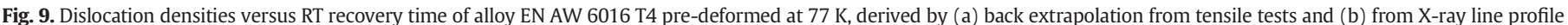
analysis of synchrotron data.

To gain a better insight into the flow onset phenomenon, we focus on the Kocks-Mecking plots of the deformation behaviour after RT recovery (Fig. 11). This allows an easier and clearer explanation of the strain hardening behaviour of the tensile test curves. Only at the beginning of straining in phase (i) of recovery the curves differ and display a higher strain hardening rate (steeper slope). Further on, the strain hardening rate in alloy EN AW 6016 T4 is equivalent in position (dislocation storage) and slope (dislocation annihilation) to the continuous tensile test under $\mathrm{LN}_{2}$ without interruption. This can be explained as follows. During deformation, moving dislocations generate vacancies. They annihilate on slowed dislocations, which leads to jogging and local climb (pinning points). The dislocation in between bows out, building loops of different Burgers vectors und tangling in the end [55]. Short RT recovery afterwards leads to a relaxation and to unkinking and untangling of dislocations [63,64], also expressed by a yield phenomenon. Removing these bowed out extra line lengths is easy; only low driving forces are needed $[65,66]$ and the subsequent strain hardening curve are left unchanged. Similar results were also found in pure aluminium cold worked at RT $[33,67]$. For short recovery times these studies showed that after an initial phase with very high strain hardening rates the curve will overlap with the original continuous straining at RT. Only at higher recovery times and higher temperatures is the RT behaviour overcome. This initial phase is explained by the transformation of a recovery of loosely tangled dislocations to a cell or subgrain structure with regular dislocation networks and a decrease in the dislocation density, followed by subgrain coarsening and growth. Compared to our results, and taking much lower temperatures into account, this means that after an initial onset (arrow in Fig. 11(a)) the strain hardening curve follows the original tensile test without RT recovery. Therefore no significant annihilation of dislocations may occur, as revealed below. The onset is likely to appear due to a slight rearrangement of dislocations leading to untangling or sharpening of cell walls.

As previously mentioned, in stage (i) there is only a minor stress drop. In the Taylor equation (Eq. (1)) the average dislocation density is proportional to the stress drop. Hence, also the calculated dislocation density will only be minimally influenced (Fig. 9(a) and Fig. 10(a)). It is important to note that this simple approach provides no insights into dislocation arrangement, and a change in strength can only be expressed through a change in dislocation density. In contrast, our synchrotron measurements (Fig. 9(b) and Fig. 10(b)) show clearly no change in the dislocation densities during heating and the first minutes of RT storage. This is compatible with the above described mechanistic of the observed flow onset phenomenon, where at the onset of recovery only detangling of dislocations is assumed to occur.
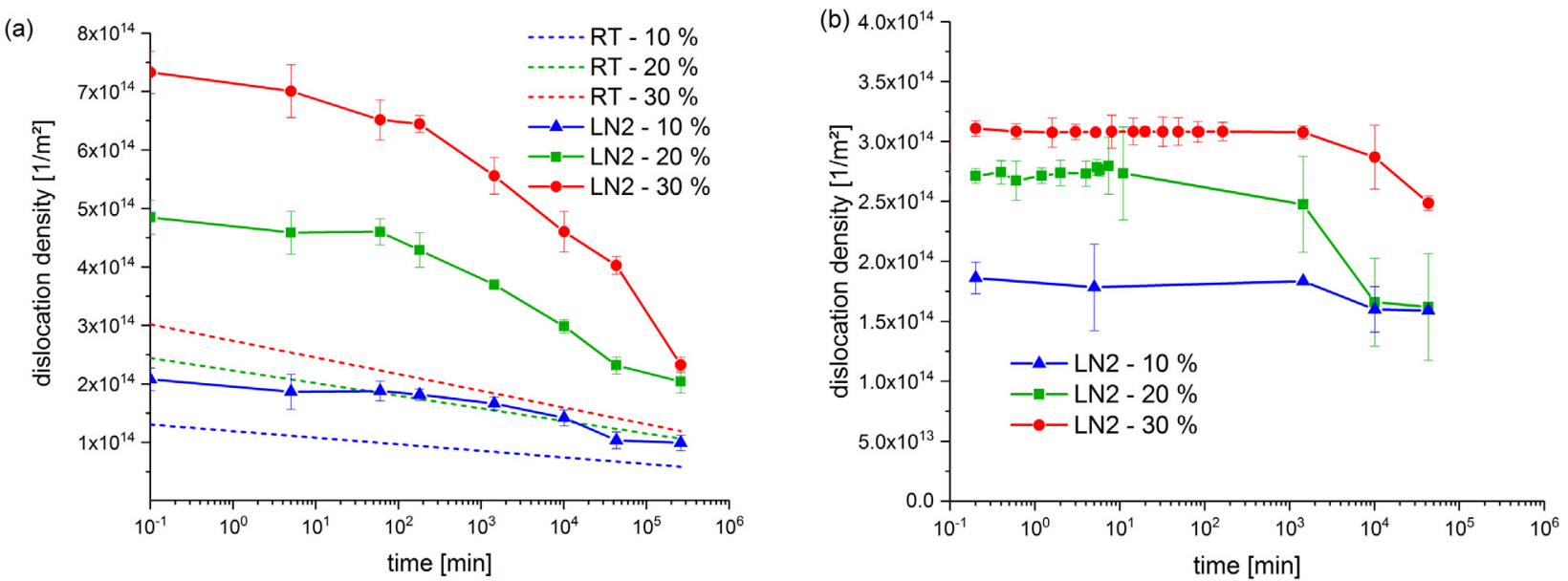

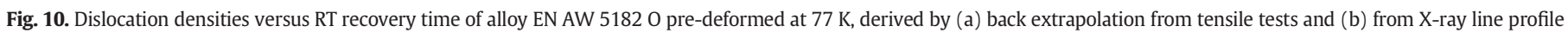
analysis of synchrotron data. 

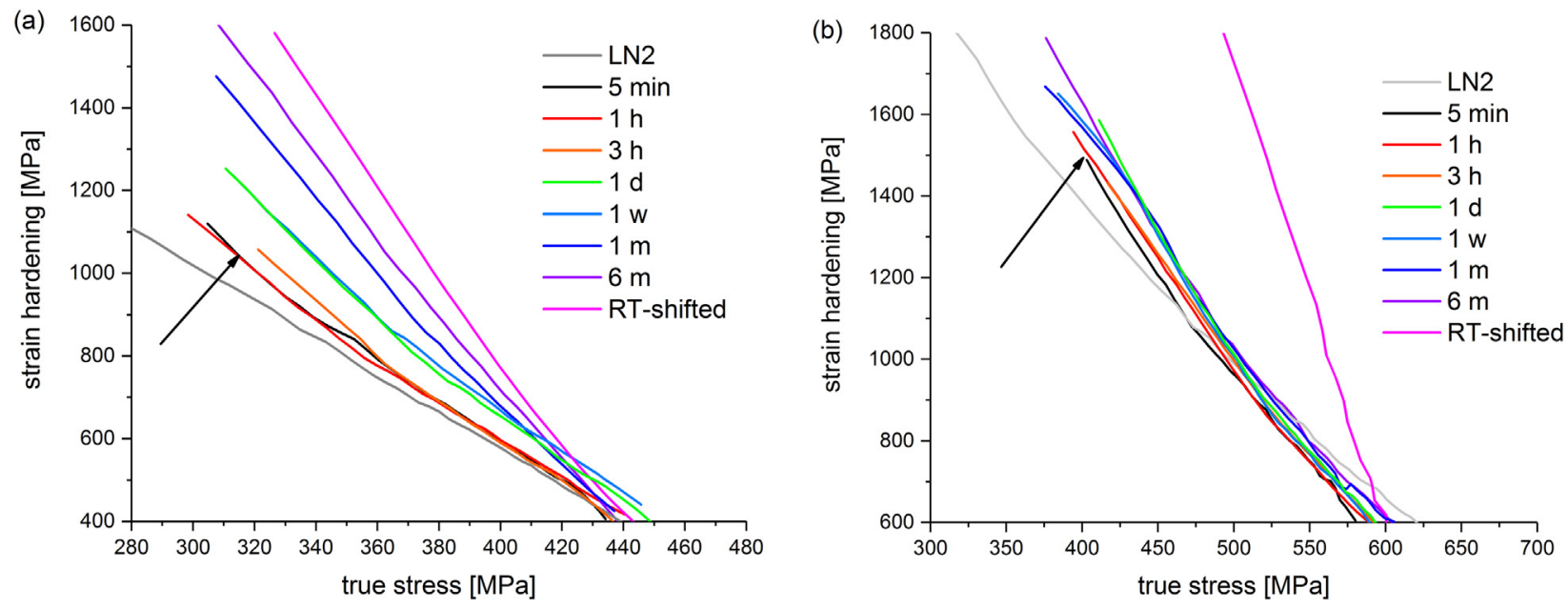

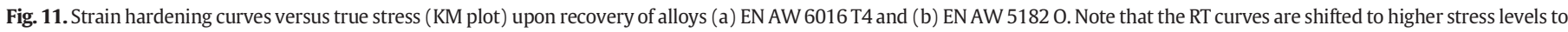

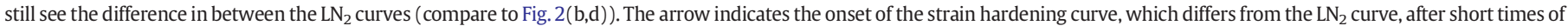
recovery (stage (i)) of up to one day.

\subsubsection{Stage II}

After stage (i) a rapid increase in recovery follows, which is referred to here as stage (ii) of recovery (Fig. 5). The change in stress drop is slightly dependent on the pre-deformation and is linked to the alloy system. Crucial for a suppressed start seems to be the dissolved magnesium in alloy EN AW 5182 O, which is known to be responsible for lower mobility of dislocations [68]. Accordingly, a higher permanent dislocation density is achieved by pre-deformation in EN AW 5182 O due to higher strain hardening (and obviously higher strength values). These aspects are assumed to generate a higher driving force and, after a longer period of moderate recovery, a sudden and stronger stress drop as seen in Fig. 5.

In stage (ii) of recovery a rapid decrease in dislocation density is calculated (Fig. 9(a) and Fig. 10(a)). This is more pronounced in alloy EN AW 5182 O. Comparing the synchrotron measurement to the results from the tensile tests in Fig. 9(b) and Fig. 10(b) provides only a rough insight into the trend of the evolution of dislocation densities, indicating a recovery process dominated by annihilation. The data from the synchrotron indicates a later onset of annihilation of dislocations as the calculations from the tensile tests. Although the absolute values are slightly shifted compared to the calculated dislocation densities, they match surprisingly well.

More insight into the dislocation arrangement is given by the strain hardening curves of the recovered samples in Fig. 11. Alloy EN AW 6016 T4 exhibits a rotation in the slope of the strain hardening curve. The slope slowly changes after one day of recovery to exhibit strain hardening characteristics which would be observed at RT deformation and therefore gives some insight into the dislocation structure involved. Please note that the RT curves are shifted along the abscissa to gain a more compact overview of the slopes. It should be noted that the shift in true stress does not affect the dislocation annihilation parameter. The behaviour of alloy EN AW 6016 T4 illustrated in Fig. 5 leads us to the conclusion that the recovery has progressed to a dislocation structure similar to that of RT-deformed samples, which is stable enough to determine the strain hardening rate during further deformation at $77 \mathrm{~K}$. With the change in slope to RT work hardening behaviour with further deformation, the maximally achievable stress is also slightly reduced because with further deformation the strain hardening decreases significantly. Hence the uniform elongation is also decreased. In contrast, alloy EN AW 51820 shows a much smaller change in strain hardening slope, which begins immediately after heating, but does not change with continuous recovery up to 6 months, and never approaches RT behaviour. As already mentioned, alloy EN AW 5182 O exhibits reduced mobility of dislocations due to the high content of $\mathrm{Mg}$ [68], and therefore less stress drop during the first few hours, but this changes after longer storage time at RT. Nevertheless, this is not visible in the strain hardening characteristics, because the $\mathrm{LN}_{2}$-deformed samples do not approach the RT curve even with longer recovery times. With further straining the recovered dislocation structure is replaced immediately with further deformation at $77 \mathrm{~K}$, also after 6 months. It may be assumed that either no stable dislocation structure is obtained after a longer recovery, as is the case with EN AW 6016 T4, or the RT curve has such a slope only due to the PLC effect, which is suppressed at lower temperatures.

\subsubsection{Stage III}

In stage three (iii) the further stress drop or dislocation reduction is comparable to RT-deformed and stored samples [55]. Because the defect density has rapidly decreased in the first two stages the driving force of the recovery decreases. The dislocation density approaches the density of RT-deformed structures (stress level difference to RT-deformed samples shown by the dashed lines in Fig. 5) and the stress drop curve turns in the direction of logarithmic behaviour $[32,55,69]$.

\subsection{RT deformation after cryogenic deformation}

In both alloys after $20 \%$ and $30 \%$ of pre-deformation at $77 \mathrm{~K}$ we observe immediate fracture at further straining at RT. Additional deformation is only possible after one day or one week of RT storage. Alloy EN AW 6016 T4 allows no direct post-straining at RT even with $10 \%$ predeformation at $77 \mathrm{~K}$, because the sample displays no net strain hardening and fracture occurs after just $2 \%$ of plastic deformation. This information is especially important in industrial processes, as the cryogenically formed component is very susceptible to failure directly after heating. This effect may require consideration in further processing of components.

Fig. 12 provides an exemplary overview of the tensile test curves of alloy EN AW 6016 T4 at RT and $77 \mathrm{~K}$ with explicit values of $10 \%$ and $20 \%$ straining. The arrows indicate the yield point of RT tensile tests after five minutes and one week of RT recovery after deformation at $77 \mathrm{~K}$. Only $10 \%$ pre-deformation at $77 \mathrm{~K}(261 \mathrm{MPa})$ generates higher strength values than the ultimate tensile strength at RT (232 MPa). Even if the thermally activated portion of the yield strength $(\approx 30 \mathrm{MPa})$ is subtracted, the stress level of the $77 \mathrm{~K}$ pre-deformed sample is still in the range of the ultimate tensile strength at RT. Shortly after prestraining at $77 \mathrm{~K}$ almost no additional deformation at RT is possible; 


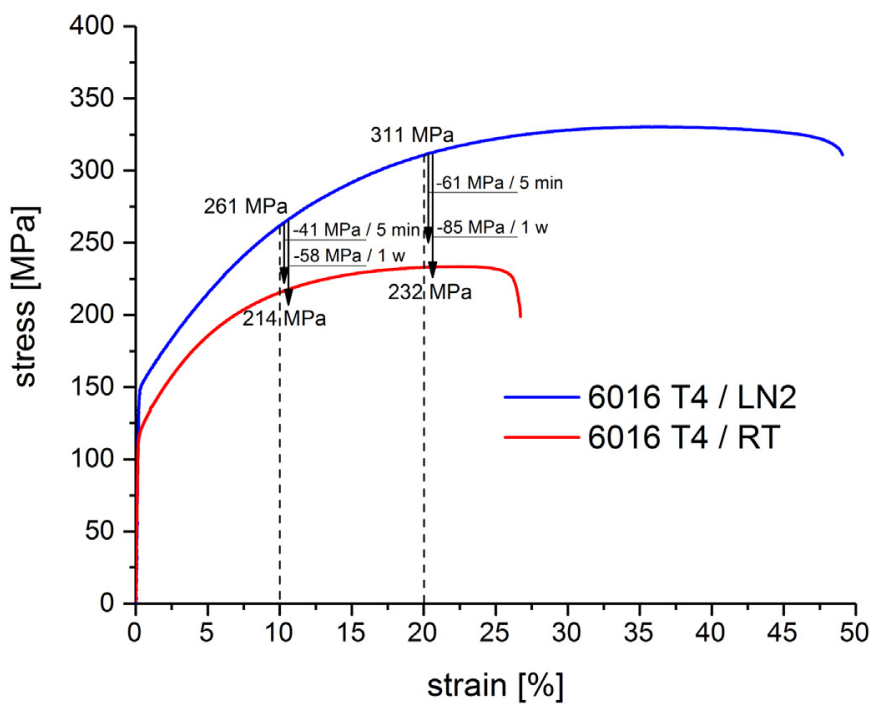

Fig. 12. Tensile test curve of alloy EN AW $6016 \mathrm{~T} 4$ at RT and at $77 \mathrm{~K}$. The arrows indicate the yield strength of RT reloading after deformation at $77 \mathrm{~K}$ and $5 \mathrm{~min}$ and $1 \mathrm{w}$ of RT recovery, respectively (RT yield strength of recovered samples).

this is shown in Fig. 6(a), where the sample fails after slight straining. If the pre-deformation is higher, the strength is far beyond the ultimate tensile strength of RT and only after short recovery times does immediate fracture at yielding occur (Fig. 6(b)). However, after 1 week of RT recovery the stress level is below the tensile test curve at RT (Fig. 12) and additional straining becomes possible. The same problem occurs in alloy EN AW 5182 O. The ultimate tensile strength at RT is reached after $10 \%$ pre-deformation, but the $\mathrm{LN}_{2}$-to-RT stress drop within the first $5 \mathrm{~min}$ of recovery is greater. Hence, immediate RT straining after $10 \%$ deformation at $77 \mathrm{~K}$ is possible.

We now consider the influence of the strain rate on the deformation or failure behaviour at post-cryogenic RT forming. In Fig. 6(a) the sample with $10 \%$ pre-deformation at $77 \mathrm{~K}$ and 5 min recovery at RT is already close to immediate fracture with roughly $2 \%$ plastic deformation and exhibits no net strain hardening. Varying the strain rate to lower and higher values reveals unusual behaviour, as shown in Fig. 8. At a low strain rate of $00.0008 \mathrm{~s}^{-1}$ the sample displays immediate fracture, but a high strain rate of $0.08 \mathrm{~s}^{-1}$ enables further plastic elongation. If softening outweighs strain hardening an unstable situation and failure will occur, otherwise further elongation could be realized.

The interplay between strain hardening and softening is schematically displayed in Fig. 13. The solid and dash-dot lines represent the strain hardening of alloys EN AW 6016 T4 and EN AW 51820 at RT, which can be assumed to be independent of the strain rate [70,71]. The solid squares indicate the recovery-related softening which occurs during the time required to deform the sample by the amount $\Delta \varphi$ in the RT tensile test. If a low strain rate is applied a longer test time is required to achieve the plastic deformation $\Delta \varphi$, which accompanies increased softening. Such a situation will result in immediate fracture. The opposite is true for high strain rates, where only a little softening can take place because of limited time. In this case, hardening outweighs softening. Finally, in Fig. 13 all forming procedures with a softening component above the strain hardening curve will result in an unstable situation, i.e. catastrophic failure, while softening conditions below the strain hardening curve could generate maintained forming capacity. In Fig. 13 the softening points for $20 \%$ pre-deformation at $77 \mathrm{~K}$ are shifted to slightly higher values compared to those of $10 \%$ pre-deformation. This takes into account the higher recovery/softening rate of the $20 \%$ deformed structure (compare the $\mathrm{LN}_{2}$-to-RT stress drop values in Fig. 6 and Fig. 7). Thus, higher deformed structures are more susceptible to failure during RT deformation for two reasons: strain hardening

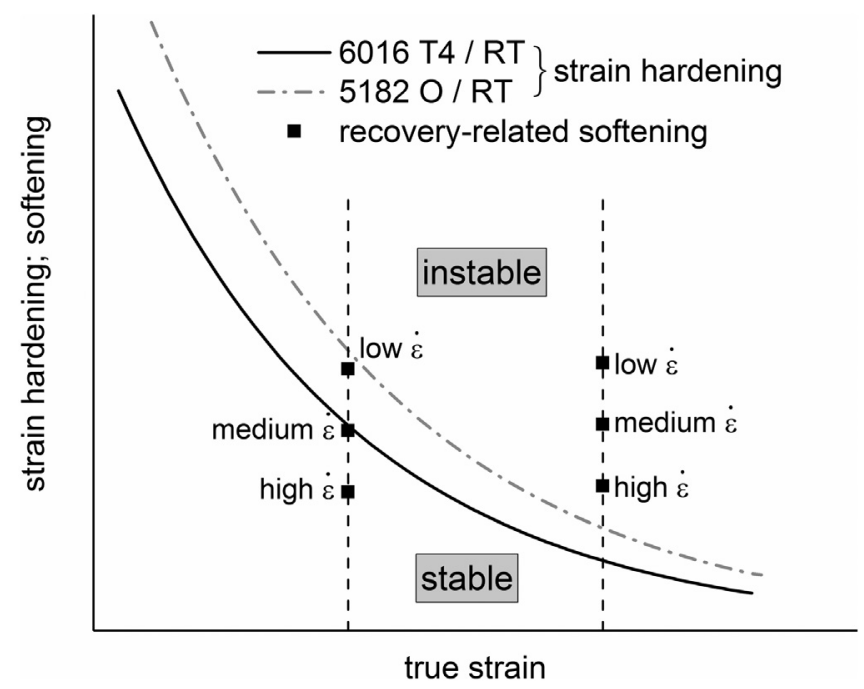

Fig. 13. Schematic illustration of strain hardening and softening over strain for the alloys tested. Strain hardening (solid and dash-dot lines) and recovery-related softening occurring during post-cryogenic RT deformation at different strain rates (points). Stable situations are below, unstable above the strain hardening lines.

decreases, and softening increases. For alloy EN AW 51820 the curve displays a higher strain hardening level, i.e. it is shifted upwards compared to EN AW 6016 T4 in Fig. 13. Consequently, this alloy is slightly less susceptible to sudden failure at RT forming after cryogenic predeformation.

\section{Conclusion}

This work investigates the room temperature recovery behaviour of cryogenically deformed Al-Mg and Al-Mg-Si alloys and thus clarifies to what extent the room temperature storage influences the mechanical and microstructural properties of the samples. Tensile test curves interrupted and recovered at room temperature show that the recovery process can be divided into three stages.

- Initial recovery processes occur due to untangling of dislocations and dislocation rearrangement (stage (i) of recovery). The length of this phase is dependent on the alloying system and the amount of predeformation.

- In the second stage of recovery (ii), a major stress drop and the main reduction of dislocation density occurs. In EN AW 6016 T4 this is accompanied by a rearrangement of dislocations, which is stable with further deformation.

- The third stage of recovery (iii) is marked by a lesser decline in strength and dislocation density which is comparable to room temperature recovery.

Room temperature tensile tests after cryogenic deformation can result in immediate fracture. Sudden failure occurs mainly when the postcryogenic RT deformation is performed soon after cryogenic forming and at low strain rates. In this case, recovery-related softening dominates strain hardening, which results in an undesirable unstable situation.

\section{Declaration of competing interest}

The authors declare that they have no known competing financial interests or personal relationships that could have appeared to influence the work reported in this paper. 


\section{Acknowledgements}

This work was funded by the Austrian Research Promotion Agency (FFG), grant number 853560 .

Financial support from the Christian Doppler Research Association, the Austrian Federal Ministry for Digital and Economic Affairs, and the National Foundation for Research, Technology and Development is also gratefully acknowledged.

We thank DESY (Hamburg, Germany), a member of the Helmholtz Association (HGF), for providing experimental facilities. Parts of this research were carried out at PETRA III using the Powder Diffraction and Total Scattering beamline P02.1. The research leading to our findings took place in the framework of project CALIPSOplus under the Grant Agreement 730872 of the EU Framework Programme for Research and Innovation HORIZON 2020. The authors would like thank Florian Schmid, Jakob Grasserbauer and Bernhard Trink, colleagues from Montanuniversität Leoben, for their assistance.

\section{Data availability}

The raw/processed data required to reproduce these findings cannot be shared at this time due to technical or time limitations.

\section{Appendix A}

As discussed in Section 3.2 it is difficult to evaluate the actual stress drop from Fig. 3 and Fig. 4 due to stress plateaus and yield points followed by a stress decrease evolution. To bypass the flow onset phenomenon, the tensile testing curves were converted into true stress/ strain curves. The flow curves after the RT recovery were fitted with a Kocks-Mecking type function. By back-extrapolation of the KM-fit to the flow onset of the recovered flow curve the difference between the stress before and after recovery (stress drop) could be evaluated. A graphical outline to illustrate the process is displayed in Fig. 14.

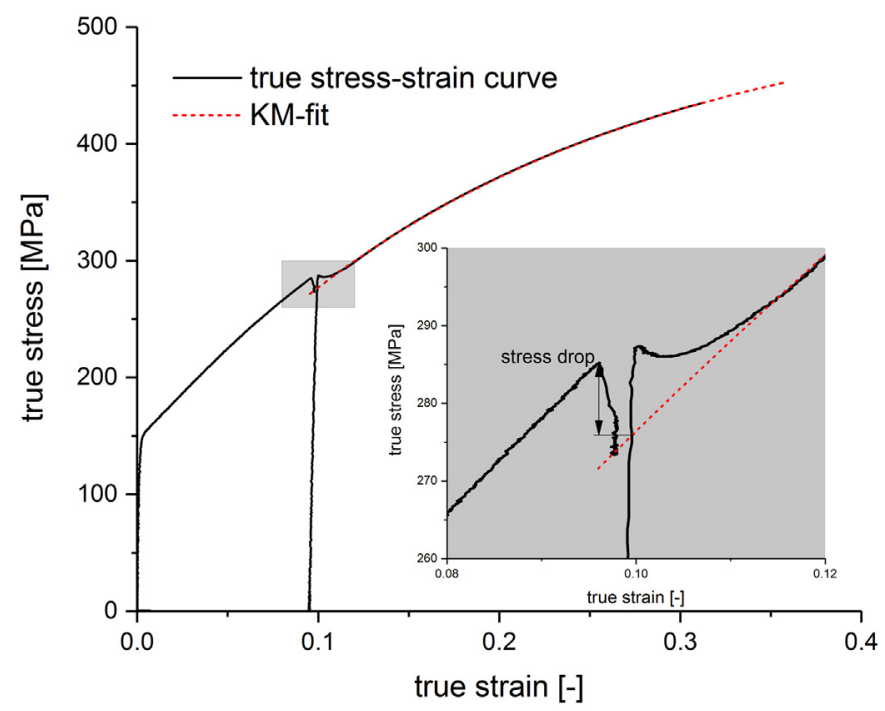

\section{References}

[1] W.S. Miller, L. Zhuang, J. Bottema, A.J. Wittebrood, Smet P. de, A. Haszler, et al., Recent development in aluminium alloys for the automotive industry, Mater. Sci. Eng. A 280 (1) (2000) 37-49, https://doi.org/10.1016/S0921-5093(99)00653-X.

[2] D. Carle, G. Blount, The suitability of aluminium as an alternative material for car bodies, Mater. Des. 20 (5) (1999) 267-272, https://doi.org/10.1016/S0261-3069 (99)00003-5.
[3] J. Hirsch, Recent development in aluminium for automotive applications, Trans. Nonferrous Metals Soc. China 24 (7) (2014) 1995-2002, https://doi.org/10.1016/ S1003-6326(14)63305-7.

[4] D. Raabe, M. Sachtleber, H. Weiland, G. Scheele, Z. Zhao, Grain-scale micromechanics of polycrystal surfaces during plastic straining, Acta Mater. 51 (6) (2003) 1539-1560, https://doi.org/10.1016/S1359-6454(02)00557-8.

[5] P. Ebenberger, P.J. Uggowitzer, S. Kirnstötter, B. Gerold, S. Zaefferer, S. Pogatscher, Processing-controlled suppression of Lüders elongation in AlMgMn alloys, Scr. Mater. 166 (2019) 64-67, https://doi.org/10.1016/j.scriptamat.2019.02.047.

[6] P. Ebenberger, P.J. Uggowitzer, B. Gerold, S. Pogatscher, Effect of compositional and processing variations in new 5182-type AlMgMn alloys on mechanical properties and deformation surface quality, Materials 12 (10) (2019)https://doi.org/10.3390/ ma12101645.

[7] Y. Birol, Pre-aging to improve bake hardening in a twin-roll cast $\mathrm{Al}-\mathrm{Mg}-\mathrm{Si}$ alloy, Mater. Sci. Eng. A 391 (1-2) (2005) 175-180, https://doi.org/10.1016/j.msea.2004. 08.069 .

[8] O. Engler, J. Hirsch, Texture control by thermomechanical processing of AA6xxx Al$\mathrm{Mg}-\mathrm{Si}$ sheet alloys for automotive applications-a review, Mater. Sci. Eng. A 336 (1-2) (2002) 249-262, https://doi.org/10.1016/S0921-5093(01)01968-2.

[9] R. Prillhofer, G. Rank, J. Berneder, H. Antrekowitsch, P.J. Uggowitzer, S. Pogatscher Property criteria for automotive Al-Mg-Si sheet alloys, Materials 7 (7) (2014) 5047-5068, https://doi.org/10.3390/ma7075047.

[10] K. Zheng, D.J. Politis, L. Wang, J. Lin, A review on forming techniques for manufacturing lightweight complex-shaped aluminium panel components, International Journal of Lightweight Materials and Manufacture 1 (2) (2018) 55-80, https://doi.org/ 10.1016/j.ijlmm.2018.03.006.

[11] S. Fu, Q. Zhang, Q. Hu, M. Gong, P. Cao, H. Liu, The influence of temperature on the PLC effect in Al-Mg alloy, SCIENCE CHINA Technol. Sci. 54 (6) (2011) 1389-1393. https://doi.org/10.1007/s11431-011-4398-9.

[12] H. Laurent, J. Coër, P.Y. Manach, M.C. Oliveira, L.F. Menezes, Experimental and numerical studies on the warm deep drawing of an Al-Mg alloy, Int. J. Mech. Sci. 93 (2015) 59-72, https://doi.org/10.1016/j.ijmecsci.2015.01.009.

[13] M. Ghosh, A. Miroux, R.J. Werkhoven, P.J. Bolt, L.A.I. Kestens, Warm deep-drawing and post drawing analysis of two Al-mg-Si alloys, J. Mater. Process. Technol. 214 (4) (2014) 756-766, https://doi.org/10.1016/j.jmatprotec.2013.10.020.

[14] K. Zheng, Y. Dong, D. Zheng, J. Lin, T.A. Dean, An experimental investigation on the deformation and post-formed strength of heat-treatable aluminium alloys using different elevated temperature forming processes, J. Mater. Process. Technol. 268 (2019) 87-96, https://doi.org/10.1016/j.jmatprotec.2018.11.042.

[15] T. Feister, H. Kim, A. Gwinn, T. Schiller, M. Austin, Failure predictions in warm forming of 7075-T6 aluminum structural parts, IOP Conference Series: Materials Science and Engineering 418 (2018), 12024. https://doi.org/10.1088/1757-899X/418/ $1 / 012024$.

[16] M. Jobba, R.K. Mishra, M. Niewczas, Flow stress and work-hardening behaviour of Al-Mg binary alloys, Int. J. Plast. 65 (2015) 43-60, https://doi.org/10.1016/j.ijplas. 2014.08.006

[17] Z. Xu, H.J. Roven, Z. Jia, Mechanical properties and surface characteristics of an AA6060 alloy strained in tension at cryogenic and room temperature, Mater. Sci. Eng. A 648 (2015) 350-358, https://doi.org/10.1016/j.msea.2015.09.083.

[18] R. Schneider, B. Heine, R.J. Grant, Z. Zouaoui, Aluminium sheet metal forming at low temperatures, IOP Conference Series: Materials Science and Engineering 74 (2015) https://doi.org/10.1088/1757-899X/74/1/012014.

[19] F. Grabner, J.A. Österreicher, B. Gruber, N. Papenberg, F. Gerstner, S. Kirnstötter, et al., Cryogenic forming of Al-Mg alloy sheet for Car outer body applications, Adv. Eng. Mater. 242 (2019) 33, https://doi.org/10.1002/adem.201900089.

[20] S. Saimoto, Deformation kinetics and constitutive relation analyses of bifurcation in work-hardening of face-centred cubic metals at cryogenic temperatures, Acta Mater. 174 (2019) 43-52, https://doi.org/10.1016/j.actamat.2019.05.029.

[21] R. Schneider, R.J. Grant, J.M. Schlosser, W. Rimkus, K. Radlmayr, F. Grabner, et al., An investigation of the deep drawing behavior of automotive aluminum alloys at very low temperatures, Metall. Mater. Trans. A 51 (3) (2020) 1123-1133, https://doi.org/ 10.1007/s11661-019-05584-4.

[22] M. Kumar, N. Sotirov, F. Grabner, R. Schneider, G. Mozdzen, Cryogenic forming behaviour of AW-6016-T4 sheet, Trans. Nonferrous Metals Soc. China 27 (6) (2017) 1257-1263, https://doi.org/10.1016/S1003-6326(17)60146-8.

[23] F. Grabner, B. Gruber, C. Schlögl, C. Chimani, Cryogenic sheet metal forming - an overview, Mater. Sci. Forum 941 (2018) 1397-1403, https://doi.org/10.4028/ www.scientific.net/MSF.941.1397.

[24] W. Cheng, W. Liu, S. Yuan, Deformation behavior of Al-Cu-Mn alloy sheets under biaxial stress at cryogenic temperatures, Mater. Sci. Eng. A 759 (2019) 357-367, https://doi.org/10.1016/j.msea.2019.05.047.

[25] R. Schneider, R.J. Grant, B. Heine, R. Börret, S. Burger, Z. Zouaoui, An analysis of the surface quality of AA5182 at different testing temperatures, Mater. Des. 64 (2014) 750-754, https://doi.org/10.1016/j.matdes.2014.08.028.

[26] K.O. Bogardus, G.W. Stickley, F.M. Howell, A review of information on the mechanical properties of aluminum alloys at low temperatures, National Advisory Committee for Aeronautics - Technical Note 2082, 1960.

[27] D.-Y. Park, M. Niewczas, Plastic deformation of Al and AA5754 between 4.2K and 295K, Mater. Sci. Eng. A 491 (1-2) (2008) 88-102, https://doi.org/10.1016/j.msea. 2008.01.065.

[28] T. Tsuchida, R. Kaneko, Temperature dependence of activation energy in stage II recovery in deformed aluminium, Phys. Status Solidi A 104 (2) (1987) 627-634, https://doi.org/10.1002/pssa.2211040213.

[29] J. Schmidt, F. Haener, Stage III-recovery of cold worked high-purity aluminium determined with a low-temperature calorimeter, Z. Physik B - Condensed Matter 81 (2) (1990) 215-222, https://doi.org/10.1007/BF01309351. 
[30] C. Panseri, S. Ceresara, T. Federighi, Recovery of aluminium cold-worked by compression at $78^{\circ} \mathrm{K}$, Il Nuovo Cimento 29 (6) (1963) 1223-1243, https://doi.org/10. 1007/BF02750518.

[31] K. Nakamura, S. Ohtaki, I. Hashimoto, H. Yamaguchi, Annealing time dependence of isochronal recovery in cold-worked aluminum, Phys. Status Solidi A 152 (2) (1995) 393-403, https://doi.org/10.1002/pssa.2211520208.

[32] E. Nes, Recovery revisited, Acta Metall. Mater. 43 (6) (1995) 2189-2207, https://doi. org/10.1016/0956-7151(94)00409-9.

[33] T. Hasegawa, U.F. Kocks, Thermal recovery processes in deformed aluminum, Acta Metall. 27 (11) (1979) 1705-1716, https://doi.org/10.1016/0001-6160(79)900853.

[34] M. Muzyk, Z. Pakiela, K.J. Kurzydlowski, Ab initio calculations of the generalized stacking fault energy in aluminium alloys, Scr. Mater. 64 (9) (2011) 916-918, https://doi.org/10.1016/j.scriptamat.2011.01.034.

[35] M. Muzyk, Z. Pakieła, K.J. Kurzydłowski, Generalized stacking fault energies of aluminum alloys-density functional theory calculations, Metals 8 (10) (2018) 823, https://doi.org/10.3390/met8100823.

[36] H. Yamaguchi, T. Tsuchida, I. Hashimoto, Y. Ohtani, S. Ohtaki, Stage II recovery of defects in cold-worked aluminum, Phys. Status Solidi A 86 (1) (1984) 237-244, https://doi.org/10.1002/pssa.2210860125.

[37] ÖNORM EN ISO 6892-3, Metallic Materials - Tensile Testing - Part 3: Method of Test at Low Temperature, 2016.

[38] G.I. Taylor, The mechanism of plastic deformation of crystals. Part I. Theoretical, Proceedings of the Royal Society A: Mathematical, Physical and Engineering Sciences 145 (855) (1934) 362-387, https://doi.org/10.1098/rspa.1934.0106.

[39] H. Mecking, U.F. Kocks, Kinteics of flow and strain-hardening, Acta Metall. 29 (1981) 1865-1875, https://doi.org/10.1016/0001-6160(81)90112-7.

[40] U.F. Kocks, H. Mecking, Physics and phenomenology of strain hardening: the FCC case, Prog. Mater. Sci. 48 (2003) 171-273.

[41] J.F. Kreyca, State Parameter Based Modelling of Stress-Strain Curves in Aluminium Alloys, PhD Thesis TU Wien, 2017.

[42] J. Kreyca, E. Kozeschnik, Analysis of the temperature and strain-rate dependences of strain hardening, Metall. Mater. Trans. A 49 (1) (2018) 18-21, https://doi.org/10. 1007/s11661-017-4402-5.

[43] J. Kreyca, E. Kozeschnik, State parameter-based constitutive modelling of stress strain curves in Al-Mg solid solutions, Int. J. Plast. 103 (2018) 67-80, https://doi. org/10.1016/j.ijplas.2018.01.001.

[44] E. Schafler, Effects of releasing the hydrostatic pressure on the nanostructure after severe plastic deformation of cu, Scr. Mater. 62 (6) (2010) 423-426, https://doi. org/10.1016/j.scriptamat.2009.12.004.

[45] Ashiotis G, Deschildre A, Nawaz Z, Wright JP, Karkoulis D, Picca FE et al. The fast azimuthal integration Python library: pyFAI. J. Appl. Crystallogr. 2015;48(Pt 2):510-9. doi:https://doi.org/10.1107/S1600576715004306.

[46] M. Wojdyr, Fityk a general-purpose peak fitting program, J. Appl. Crystallogr. 43 (5) (2010) 1126-1128, https://doi.org/10.1107/S0021889810030499.

47] G. Ribárik, T. Ungár, J. Gubicza, MWP-fit: a program for multiple whole-profile fitting of diffraction peak profiles by ab initio theoretical functions, J. Appl. Crystallogr. 34 (5) (2001) 669-676, https://doi.org/10.1107/S0021889801011451.

48] J. Gubicza, Practical applications of X-ray line profile analysis, Information Resources Management Association. Materials Science and Engineering: Concepts, Methodologies, Tools, and Applications, IGI Global, Hershey, Pennsylvania 2017 pp. 1094-1132.

[49] M.B. Kerber, MJ. Zehetbauer, E. Schafler, F.C. Spieckermann, S. Bernstorff, T. Ungar, $\mathrm{X}$-ray line profile analysis-an ideal tool to quantify structural parameters of nanomaterials, JOM 63 (7) (2011) 61-70, https://doi.org/10.1007/s11837-0110115-1.

[50] M. Kerber, F. Spieckermann, R. Schuster, B. Joni, N. Schell, E. Schafler, In-situ synchrotron profile analysis after high-pressure torsion deformation, Crystals 9 (5) (2019) 232, https://doi.org/10.3390/cryst9050232.

[51] Q. Zhao, Cluster strengthening in aluminium alloys, Scr. Mater. 84-85 (2014) 43-46, https://doi.org/10.1016/j.scriptamat.2014.04.018.
[52] A. de Vaucorbeil, C.W. Sinclair, W.J. Poole, Atomistic insights into cluster strengthening in aluminum alloys, Materialia 4 (2018) 566-574, https://doi.org/10.1016/j. mtla.2018.11.020.

[53] H. Asada, R. Horiuchi, H. Yoshinaga, S. Nakamoto, Flow stress in Al-Mg alloy single crystals, Trans. Jpn. Inst. Metals 8 (3) (1967) 159-166, https://doi.org/10.2320/ matertrans1960.8.159.

[54] M. Verdier, Y. Brechet, P. Guyot, Recovery of AlMg alloys: flow stress and strainhardening properties, Acta Mater. 47 (1) (1998) 127-134, https://doi.org/10.1016/ S1359-6454(98)00350-4.

[55] D. Kuhlmann-Wilsdorf, The connection between recovery and glide type in aluminum and Al-Mg, Mater. Sci. Forum 331-337 (2000) 689-702, https://doi.org/10. 4028/www.scientific.net/MSF.331-337.689.

[56] G. Falkinger, P. Simon, Static recovery of an AlMg4.5Mn aluminium alloy during multi-pass hot-rolling, Procedia Engineering 207 (2017) 31-36, https://doi.org/10. 1016/j.proeng.2017.10.733.

[57] M. Verdier, J.A. Sæter, M. Janeček, Y. Bréchet, P. Guyot, D. Duly, et al., Kinetics and microstructural aspects of recovery in $\mathrm{Al}, \mathrm{Al}-\mathrm{Mg}$ and $\mathrm{Al}-\mathrm{Mn}$ alloys, Mater. Sci. Forum 217-222 (1996) 435-440, https://doi.org/10.4028/www.scientific.net/MSF. 217-222.435.

[58] S. Bai, Z. Liu, X. Zhou, Y. Gu, D. Yu, Strain-induced dissolution of Cu-Mg co-clusters and dynamic recrystallization near a fatigue crack tip of an underaged $\mathrm{Al}-\mathrm{Cu}-\mathrm{Mg}$ alloy during cyclic loading at ambient temperature, Scr. Mater. 64 (12) (2011) 1133-1136, https://doi.org/10.1016/j.scriptamat.2011.03.012.

[59] W. Huang, Z. Liu, L. Xia, P. Xia, S. Zeng, Severe plastic deformation-induced dissolution of $\theta^{\prime \prime}$ particles in Al-Cu binary alloy and subsequent nature aging behavior, Mater. Sci. Eng. A 556 (2012) 801-806, https://doi.org/10.1016/j.msea.2012.07.070.

[60] W.A. Curtin, D.L. Olmsted, L.G. Hector, A predictive mechanism for dynamic strain ageing in aluminium-magnesium alloys, Nat. Mater. 5 (11) (2006) 875-880, https://doi.org/10.1038/nmat1765.

[61] R. Swiatek, M. Zehetbauer, B. Mikulowski, Work hardening by deformation induced vacancies in low temperature deformed aluminium single crystals, Mater. Sci. Eng. A 234-236 (1997) 441-444, https://doi.org/10.1016/S0921-5093(97)00166-4.

[62] Y. Nagai, M. Murayama, Z. Tang, T. Nonaka, K. Hono, M. Hasegawa, Role of vacancysolute complex in the initial rapid age hardening in an $\mathrm{Al}-\mathrm{Cu}-\mathrm{Mg}$ alloy, Acta Mater. 49 (5) (2001) 913-920, https://doi.org/10.1016/S1359-6454(00)00348-7.

[63] I.R. Kramer, C.L. Haehner, Low temperature recovery of polycrystalline aluminum, Acta Metall. 15 (2) (1967) 199-202, https://doi.org/10.1016/0001-6160(67) 90192-7.

[64] M. Zehetbauer, D. Trattner, Effects of stress-aided static recovery in iteratively coldworked aluminium and copper, Mater. Sci. Eng. 89 (1987) 93-101, https://doi.org/ 10.1016/0025-5416(87)90253-9.

[65] M. Niewczas, D.-Y. Park, Flow stress and electrical resistivity in plastically deformed Al subjected to intermittent annealing, Mater. Sci. Eng. A 706 (2017) 256-268, https://doi.org/10.1016/j.msea.2017.09.003.

[66] V. Hašlar, P. Vostrý, High temperature stages in recovery spectrum of cold worked Al, Czechoslov. J. Phys. 38 (4) (1988) 413-416, https://doi.org/10.1007/ BF01605416.

[67] T.V. Cherian, P. Pietrokowsky, J.E. Dorn, Some observations on the recovery of cold worked aluminum, Metals Transactions 185 (1949) 948-956, https://doi.org/10. 1007/BF03398414.

[68] D.L. Olmsted, L.G.H. Jr, W.A. Curtin, R.J. Clifton, Atomistic simulations of dislocation mobility in Al, Ni and Al/Mg alloys, Model. Simul. Mater. Sci. Eng. 13 (3) (2005) 371, https://doi.org/10.1088/0965-0393/13/3/007.

[69] W.J. Poole, M. Militzer, M.A. Wells, Modelling recovery and recrystallisation during annealing of AA 5754 aluminium alloy, Mater. Sci. Technol. 19 (10) (2003) 1361-1368, https://doi.org/10.1179/026708303225005980.

[70] Y. Chen, A.H. Clausen, O.S. Hopperstad, M. Langseth, Stress-strain behaviour of aluminium alloys at a wide range of strain rates, Int. J. Solids Struct. 46 (21) (2009) 3825-3835, https://doi.org/10.1016/j.ijsolstr.2009.07.013.

[71] R.C. Picu, G. Vincze, F. Ozturk, J.J. Gracio, F. Barlat, A.M. Maniatty, Strain rate sensitivity of the commercial aluminum alloy AA5182-O, Mater. Sci. Eng. A 390 (1-2) (2005) 334-343, https://doi.org/10.1016/j.msea.2004.08.029. 